Please do not remove this page

RMIT

UNIVERSITY

\title{
Innovative flight test instrumentation and techniques for airborne laser systems performance analysis and mission efectiveness evaluation
}

Sabatini, Roberto

https://researchrepository.rmit.edu.au/esploro/outputs/9921862247801341/filesAndLinks?institution=61RMIT_INST\&index=null

Sabatini, R. (2014). Innovative flight test instrumentation and techniques for airborne laser systems performance analysis and mission efectiveness evaluation. Proceedings of 2014 IEEE International Workshop on Metrology for Aerospace, MetroAeroSpace 2014, 1-17.

https://doi.org/10.1109/MetroAeroSpace.2014.6865886

Document Version: Accepted Manuscript

Published Version: https://doi.org/10.1109/MetroAeroSpace.2014.6865886

Repository homepage: https://researchrepository.rmit.edu.au

(C) 2014 IEEE

Downloaded On 2023/04/26 09:12:14 +1000 
Thank you for downloading this document from the RMIT Research Repository.

The RMIT Research Repository is an open access database showcasing the research outputs of RMIT University researchers.

RMIT Research Repository: http://researchbank.rmit.edu.au/

\section{Citation:}

Sabatini, R 2014, 'Innovative flight test instrumentation and techniques for airborne laser systems performance analysis and mission efectiveness evaluation', in Stephen Dyer (ed.) Proceedings of 2014 IEEE International Workshop on Metrology for Aerospace, MetroAeroSpace 2014, United States, 29-30 May 2014, pp. 1-17.

See this record in the RMIT Research Repository at: https://researchbank.rmit.edu.au/view/rmit:28757

Version: Accepted Manuscript

Copyright Statement: (C) 2014 IEEE

Link to Published Version:

http://dx.doi.org/10.1109/MetroAeroSpace.2014.6865886 


\title{
Innovative Flight Test Instrumentation and Techniques for Airborne Laser Systems Performance Analysis and Mission Effectiveness Evaluation
}

\author{
Invited Keynote Lecture \\ Roberto Sabatini \\ RMIT University \\ School of Aerospace, Mechanical and Manufacturing Engineering \\ Melbourne, Victoria, Australia \\ roberto.sabatini@rmit.edu.au
}

\begin{abstract}
The extraordinary progress experienced in recent years in the field of lasers and infrared sensors, have led to the development of numerous active and passive electro-optical systems for civil and military aerospace applications. In the military domain, these developments have emphasised the need for flight instrumentation and ground control systems capable of supporting system test and training activities in operationally representative and wholly safe conditions at the ranges. This paper presents the main achievements of the PISQ Laser Test and Evaluation Range (PILASTER) research and development program. In particular, after a brief description of the PILASTER system requirements, the mathematical models and the hardware/software developed for system performance evaluation and eye-safety analysis are presented, including the novel techniques introduced for accurate measurement of laser energy and geometric characteristics in various weather conditions and operational scenarios (pointing accuracy, total energy, spot spreading, etc.). Additionally, the PILASTER subsystems hardware and software architectures are introduced, followed by a brief overview of the laboratory, ground and flight test activities performed for the PILASTER formal verification and acceptance.
\end{abstract}

\section{INTRODUCTION}

Since the late 90 's, in response to the rapid development and introduction into service of a variety of airborne electrooptical sensors and weapon systems (laser target designators, laser radars, IR/laser guided weapons, forward looking infrared, night vision imaging systems, etc.), the Italian Ministry of Defence identified the need for comprehensive, safe and operationally representative test and training activities at the ranges [1-7]. Therefore, a research and development program was launched and supported by international cooperation between the Italian Air Force Flight Test Centre (Pratica di Mare AFB), the NATO Research and Technology Organization (Flight Test Technology Team), Cranfield University (Defence Academy of the UK), RMIT University and various industrial partners, for the Design, Development, Test and Evaluation (DDT\&E) of a fully instrumented Laser Test and Training Range (LTTR) for the Italian Air Force and for other NATO Military Forces. The range area selected for this program was Poligono Interforze del Salto di Quirra (PISQ) in the Island of Sardinia, where new facilities where added to carry out safe experimental and training activities with the laser and IR systems under development or already in service with the Italian Air Force (ItAF) on its tactical aircraft and helicopters. Other national or international customers are allowed to use the new facilities on a case-by-case basis and according to international cooperation agreements in force at the time concerned. The PISQ LASer Test and Evaluation Range (PILASTER) program included the following main phases:

- Initial feasibility study

- System requirements definition

- Eye-safety analysis and performance prediction models development

- Sub-systems architecture definition

- Sub-systems detailed design (hardware and software)

- Laboratory and ground test of electro-optical sensors and electronics sub-systems

- Infrastructure development and systems integration

- Development of analysis tools and simulation software (performance evaluation and safety assessment)

- Formal verification and acceptance test

\section{OPERATIONAL AND TECHNICAL REQUIREMENTS}

The PILASTER concept of operation is depicted in Fig. 1. The on-board operator of a training/experimental aircraft aims the Airborne Laser Target Designator (A-LTD) system at the centre of a cooperating target. A Laser Safety Officer (LSO), located at the PISQ Control Centre (PCC) verifies that the laser is aimed at the proper target and that the target lock-on status has been achieved. For this purpose, a real-time videolink (video telemetry ground unit) is available between the aircraft and the PCC for safe operations. The LSO then authorises activation of the laser system. Should the video-link be unavailable, as in the case of a Ground Laser Target Designator (G-LTD) system operated from a ground Forward Air Controller (FAC) or a training aircraft not equipped with the video telemetry unit, the LSO may authorise the laser activation upon receiving confirmation (via voice/data link) that the planned target has been unambiguously recognised and aimed to by the aircraft Pilot/Weapon Systems Operator (WSO) or by the ground FAC. The Sensor Tracking and Measurement Unit (STU) determines the laser spot spatial energy distribution, calculating the spot centroid as well as its 
position with respect to the target centre (global pointing error). The captured laser spots and the others applicable measurements are recorded. During the laser activation, the STU sends the relevant laser spot parameters (i.e., dimension and position with respect to the target centre) to the Monitoring and Control Station Unit (MSU), located at the PCC. These parameters are represented on the MSU display to allow the LSO to supervise the operations.

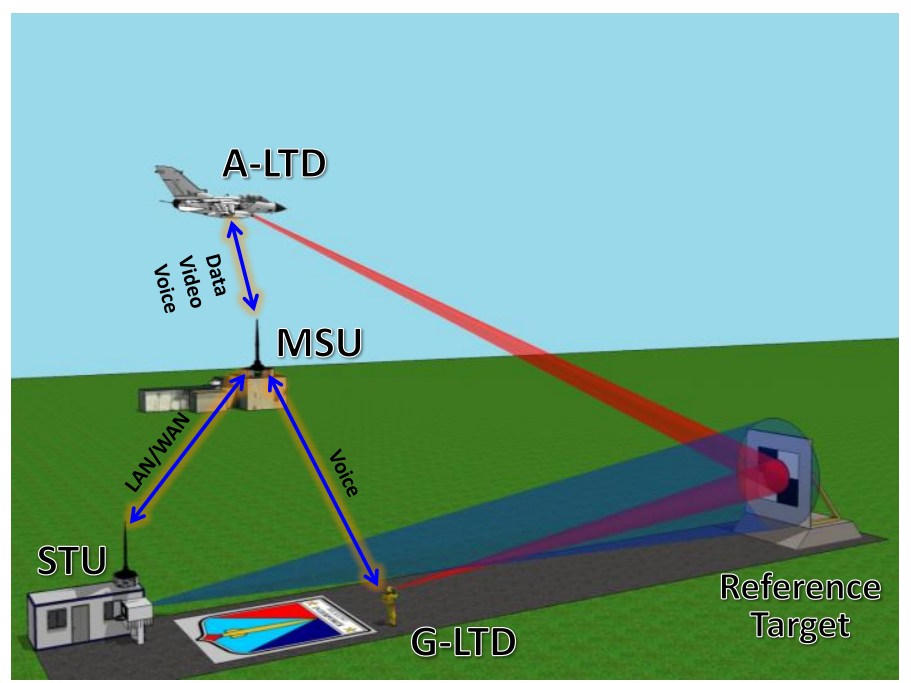

Fig. 1. PILASTER Concept of Operations. Adapted from [1].

When the laser spot approaches the target peripheral zones and the LSO believes there is a possibility for the laser spot to fall outside the target itself, he might order the WSO/FAC to deactivate the laser (through the voice/data link). Training with both self-designation and cooperative attacks is possible, both by laser guided inert weapon releasing and by simulated attacks. In self-designation attacks, the aircraft follows the flight plans up to the optimal (continuously computed) release point for the inert Laser Guided Weapon (LGW). Then, it performs the escape manoeuvre, activating the airborne laser designator at a proper time. In cooperative attacks, the lead aircraft releases the weapon and a spiker aircraft performs illumination as required for an effective guidance towards the designated target. During this type of attack, the two aircraft manoeuvre as required by the planned tactics. In both selfdesignation and cooperative attacks with inert weapon delivery, the STU starts measuring and recording the laser spot applicable parameters (e.g. spot centroid, time of laser activation, time of laser deactivation, etc.). Measurement of the attack radial error is performed by detecting the target/ground impact point of the laser-guided weapon. Consequently, one (or more) high-speed digital TV camera(s) are used at the STU to collect images of a relevant volume around the target. In simulated self-designation attacks, the aircrew follows the flight plans up to the optimal estimated release point, and then simulates the release and manoeuvres as if it had occurred. At the required time, the pilot/WSO performs target illumination. In cooperative simulated attacks, the spiker aircraft performs illumination as required and both leader and spiker aircraft manoeuvre following the planned training tactics. For both self-designation and cooperative attacks, the following information shall be supplied to the MSU:

- During the entire attack, the aircraft (self-designation) or the leader/spiker (cooperative) flight trajectory parameters up to the instant of release, from an available data-link, the PISQ Radars/Cinetheodolites or other TSPI systems, such as GPS/INS or Differential GPS (DGPS) position reference systems [3, 7-9].

- At the instant of simulated release, with a synchronous signal (SRTOA), from an available data-link or manually from a PCC operator (using the voice-link with the aircrew).

- After the simulated release, with the laser activation time signal (LATOA), marking the beginning of the laser designation, and the detected laser spot parameters until designation is completed (planned designation time). The LATOA signal will be supplied either by the available data-link or by means of the voice-link with the aircrew/FAC. Should the laser spot on the target be undetected by the STU sensors (when expected to be on the target), a warning signal shall be sent to the PCC, allowing the LSO to order the immediate laser deactivation (emergency procedure). In both normal and emergency procedures, the time of laser deactivation (LDTOA) shall be supplied, with similar modalities (data-link/voice-link), and confirmed as well by the STU sensors.

- Before mission is initiated, with the relevant atmospheric parameters in the area of operations (visibility, relative humidity, air temperature, wind speed/direction, etc.) and target parameters (reflectivity, geometry, etc.).

- The MSU then calculates the optimal Weapon Release Corridor (WRC) taking into account the leader flight parameters and gives an output of the computed errors in quasi-real-time (i.e. before the beginning of a new releasing exercise, within 1 minute) if data-link is available, or in deferred time (i.e. post-mission analysis performed using the data of all releasing exercises) if data-link is unavailable.

\section{A. Self-designation attacks}

In self-designation attacks, the flight crew is supplied with the information listed below:

a. The calculated optimal time of release (and the difference with the real one), keeping fixed all flight parameters, taking into account the designation time and STU detected laser spot characteristics (on target).

b. The calculated optimal aircraft speed (ground speed) at the simulated time of release (and the difference with the real one), keeping fixed all the other flight and designation parameters.

c. The calculated optimal aircraft designation time and range envelope (distances from the target outside the simulated target lethal-range but within the maximum 
range for an effective designation) and the differences with the real designation time and profile.

\section{B. Cooperative Attacks (Air Spiker and FAC)}

In cooperative attacks, the flight crew is supplied with the information listed below:

a. The calculated optimal time of release (and the difference with the real one), taking into account the spiker designation time and STU detected laser spot characteristics (on target), keeping fixed all flight parameters.

b. The calculated optimal weapon carrying aircraft speed (ground speed) at the simulated time of release (and the difference with the real one), keeping fixed all the other flight parameters and laser designation parameters.

c. The calculated optimal designation time and range envelope (distances from the target outside the simulated target lethal-range but within the maximum range for an effective designation) and the differences with the real designation time and profile.

\section{Experimental Missions}

For experimental flight and ground test activities, in addition to the aforementioned mission effectiveness data, PILASTER allows direct or indirect measurement of all applicable laser parameters, such as the laser spot dimensions, energy distribution and centroid position, laser spot quality, atmospheric extinction, and PRF/code-signal on the target.

\section{PILASTER COMPOSITION}

PILASTER is designed to operate with present generation laser systems/weapons and its modular/expandable design allows future upgrades for test and training operations with the next generations of laser, IR/EO and multisensor systems. According to the general description and concept of operation previously illustrated, the PILASTER is composed by the following main systems:

a. Modular target(s) for real attacks (weapon delivery);

b. Permanent target(s) for simulated attacks (no weapon delivery);

c. Permanent/mobile laser Sensor and Tracking Unit(s) (STU);

d. Monitoring Control and Display Station Unit (MSU);

e. LAN/WAN (between MSU and STU);

f. Video-link (aircraft to MSU) with encryption (on-board module) and decryption (ground module);

g. Voice-link (V/UHF radio communications);

h. Data-link (LINK-16, MIDS and others) [10]

i. DGPS position reference system;

j. Meteorological sensor stations.

Furthermore, the use of a bi-directional data-link (MSUAircraft) and Encryption/Decryption of the video-link are considered as growth options for future PILASTER upgrade programs. In order to fulfil the various test/training mission requirements, the following different kinds of targets are used:

- Fast-recoverable Target (FRCT). This type of target is used for inert laser-guided weapon releasing, and have a Mean Time To Repair (MTTR) of 1 hour;

- Fixed Target (FXDT). This type of target is used for simulated laser-guided weapon releasing;

- Destroyable Target (DEST). This target simulates a tactical target, and is used for releasing laser-guided weapons with their normal (or reduced) warhead explosive charges;

- IR Reference Target (IREF). Using this target the Minimum Resolvable Temperature Differences (MRTD) and Spatial Frequencies (corresponding to various 2-D discrimination levels), can be determined for the FLIR systems integrated with airborne laser systems

- Acquisition Training Target (ATGT). This kind of target simulates a tactical target for acquisition training (i.e. shelter, tank, bridge, etc.).

Both the FRCT and FXDT have a dimension of approximately $10 \times 10 \mathrm{~m}^{2}$ in order to be extended for the majority of laser systems (ground and airborne) currently in service, at most ranges and grazing angles of practical interest. Furthermore, they will be painted with a highly diffusive paint of known reflection properties (i.e., reflectance and BRDF), in order to allow STU spot energy measurements. The DEST and ATGT targets shall have dimensions and shapes appropriate to simulate real targets and to perform real-time (in flight) and post-mission damage-assessment (DEST). The IREF target shall be a standard IR multiple bars target, whose bars shall be heated at precisely tuneable temperature differences $(\Delta T)$ with respect to the background.

\section{A. Sensor Tracking and Measurement Unit}

The STU is positioned nearby the targets. A hardened location (e.g., bunker) is constructed nearby the FRCT and DEST targets. The STU is composed by the following elements:

a. IR and TV cameras;

b. Detector arrays and processing units (FXDT target only);

c. Computing and recording systems;

d. Data acquisition and processing application software.

The STU calculates the position of the laser spot energy centroid with respect to the target centre. A representation of this position within the target is supplied in real-time to the MSU. The STU also determines and records the laser spot geometric dimensions on the target. Using the FXDT detectors array, the STU provides laser energy measurements (on the target) and therefore allows, in post-processing, atmospheric extinction determination (by comparison with the known aircraft/system coordinates). Furthermore, the FXDT detectors perform PRF measurements for pulsed laser systems. All these measurements allow verifying the impact of atmospheric and operational mission parameters on systems effectiveness. The STU is capable of analysing signals from Near Infrared (NIR) lasers operating at $1.064 \mu \mathrm{m}$ (non eye-safe spectral region) and 1.54-1.57 $\mu \mathrm{m}$ (eye-safe region). Additionally, provisions 
are made for operation with other NIR, Mid-Infrared (MIR) and Far-Infrared (FIR) lasers.

\section{B. Monitoring and Control Station Unit}

The MSU is installed in the PCC building. It receives data from the STU and shows, on dedicated displays, the laser spot on the target and the video signal received from the aircraft (video-link). Particularly, the MSU is capable of:

- $\quad$ showing, simultaneously on the same display, the data output coming from at least two different STU positions;

- providing aural/visual warnings to the LSO when the expected laser signal is not detected by the STU;

- showing in real-time the video signal received from the aircraft (video-link), on a dedicated display.

The MSU is also designed to accommodate the automatic deactivation of the on board laser armament, when critical safety conditions are detected (growth option). The MSU is basically composed of:

- a computer based workstation with a powerful CPU, high-speed graphic and recording capabilities, analogue and digital I/O and LAN/WAN interfaces;

- a video-link ground unit;

- a voice-link (V/UHF radio) ground unit;

- data link communications (LINK-16 and others).

\section{LAN/WAN Networks}

PILASTER is equipped with various local or wireless area networks (LAN/WAN) to interconnect the STU and MSU. The choice and combination of LAN/WAN networks for each test/training mission case is based on the available bandwidth for real-time and post-processed data transfer from the available STU/MSU locations.

\section{Sensors}

In order to perform measurements of the relevant parameters, PILASTER employs two meteorological stations, both equipped with the sensors necessary for accurate measurement of temperature $(T)$, pressure $(P)$, wind speed $\left(W_{s}\right)$, relative humidity $(R H)$, rainfall rate $(\Delta x / \Delta t)$, and turbulence structure constant $\left(C_{n}\right)$. Each of the two groups of sensors is mounted on a tower with height adjustable between 0 and 8 metres. For trials/training activities with ground laser systems, the sensor towers are placed at the target and laser system locations, and all data relative to the two locations are gathered and recorded at the meteorological stations. During trials/training missions with airborne laser systems, only the data relative to the relevant target(s) location(s) are recorded. All collected meteorological data are used for post-mission analysis of laser beam atmospheric propagation performance.

\section{E. Aircraft Video Link}

PILASTER is equipped with a Real-time Video Link from the aircraft to the MSU, to allow Safety and Trial Officers (in the PCC) to monitor and control the whole laser test/training operations. Two functional blocks are present: an On-board Unit installed on the training/experimental aircraft, and a Ground Unit installed in the PCC and interfaced with the MSU. Provision for additional encryption/decryption modules for the video signals is also incorporated in the system.

\section{F. Voice Link}

The voice-link between the aircraft and the MSU is provided by installing a multiband V/UHF radio communication system (including the relative antenna and control panel) at the PCC. The system is fully compatible with radio-communication systems currently installed on-board aircraft with $8.33 \mathrm{kHz}$ channel spacing in the ATC band and $25 \mathrm{kHz}$ channel spacing in the other bands.

\section{G. Data-Link}

The data-link is used to perform the following functions:

a. To maximise laser safety, the MSU has the capability of controlling the laser/armament operative modes, such as Laser ON/OFF, Track Mode, Lock-On or Track Lost signals. For this purpose, the MSU is capable of integrating dedicated $\mathrm{HW} / \mathrm{SW}$ modules for analysing in real time MIL-STD-1553/1760 or other data bus messages exchanged between the laser system and the on-board mission computer via data-link (LINK-16 or other).

b. To perform real-time attack simulations (self-designation or cooperative), the MSU has the capability of acquiring in real-time the significant flight parameters, by reading the applicable bus messages (MIL-STD-1553 or other avionic bus). In order to provide the crew(s) with quasi real-time feedback during simulated attacks, the relevant MSU outputs can be also sent to the aircraft.

The STU subsystem architecture is depicted in Fig. 2. The main sensors are two Near Infrared (NIR) cameras, the detectors array on the FXDT and a high-speed TV camera.

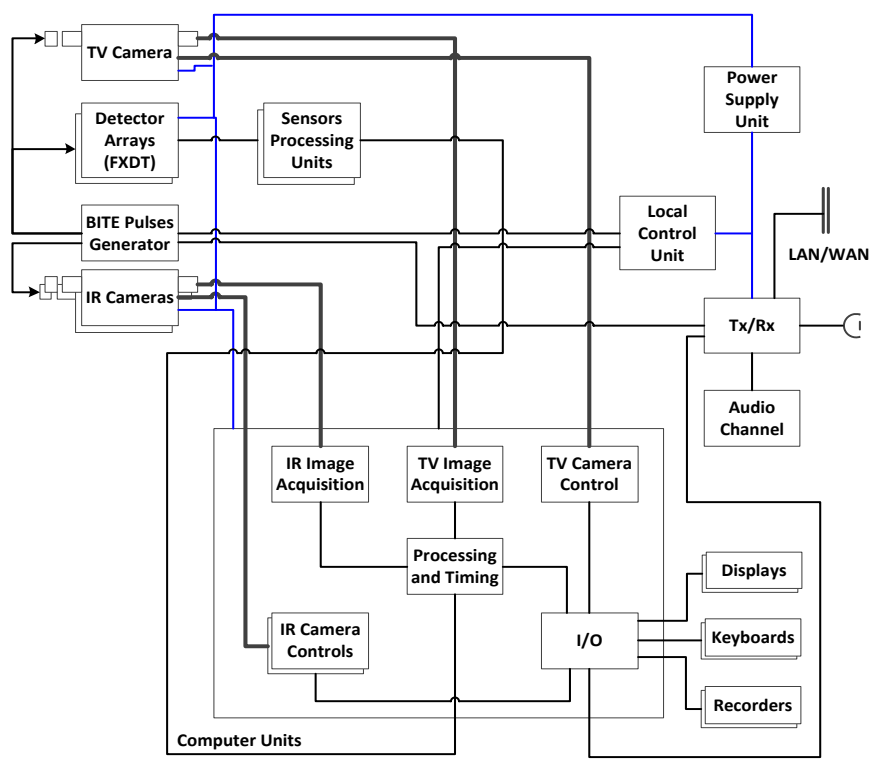

Fig. 2. STU subsystem architecture. Adpated from [1].

All STU sensors and other key components for the system Built-In Test (BITE) are connected with the relative control units and to a computer which performs the necessary calculations for the energy and geometry parameters of the laser spot. Outputs are then fed through the radio (WAN) and, 
subsequently to the PISQ LAN network. The MSU subsystem includes the LAN/WAN interfaces, the processing units, the laser data presentation and recording, as well as other devices for real-time monitoring and post-mission analysis of the experimental data. In particular, the MSU is equipped with a telemetry system to retrieve the data acquired by the airborne Flight Test Instrumentation (FTI), as well as a DGPS trajectory recorder and the necessary data-link connectivity. The MSU architecture is depicted in Fig. 3.

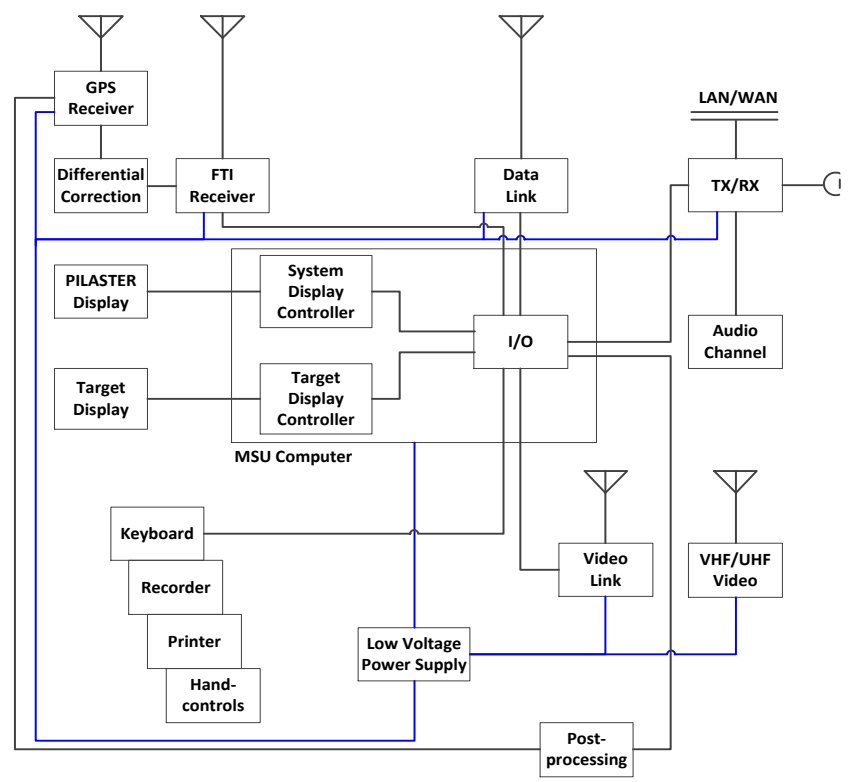

Fig. 3. MSU subsystem architecture. Adapted from [1].

The acquired data are processed through suitable mathematical models, allowing the determination of the following laser characteristics:

- Total incident energy (and atmospheric transmittance)

- Geometric and energy centre of the laser spot

- Aiming accuracy (deviation from the aiming point)

Three alternative Energy Measurement Techniques (EMT) were developed to determine the total incident laser energy and, subsequently, the atmospheric transmittance. The first two techniques, EMT-1 and EMT-2, are based on the direct measurement of the laser energy incident on calibrated target surfaces of $8 \times 8 \mathrm{~m}$ (airborne and ground-based systems); whereas EMT-3 is based on $4 \times 4 \mathrm{~m}$ surfaces (ground-based systems only) made in Spectralon ${ }^{T M}$ (reflectance close to $100 \%$ in the IR spectrum). In EMT-1, an IR-camera precalibrated for radiance measurements is used in conjunction with a highly selective filter (laser wavelength) to detect the laser spot energy on the target and to generate a Pixel Intensity matrix (PIM) in high resolution greyscale format (Fig. 4). The IR-camera calibration required for EMT-1 is an experimental procedure that allows determination of the Integrated Radiance Response Function (AIRF) [1, 11]. The response of a single pixel in terms of Analogue Digital Unit (ADU) is:

$$
\operatorname{ADU}_{i, j} \propto \frac{\mathrm{A}}{4 \cdot \mathrm{f} \#^{2}+1} \cdot \mathrm{g} \cdot \mathrm{i}_{\text {time }} \cdot \int_{\lambda 1}^{\lambda 2} \tau_{\lambda} \eta \cdot \mathrm{E}_{\lambda} \mathrm{d} \lambda
$$

where:

$\lambda=$ wavelength

$\lambda_{1}, \lambda_{2}=$ limits of the IR-camera spectral band filter

$\eta_{\lambda}=$ detector quantum efficiency

$E_{\lambda} \quad=$ spectral radiance

$\tau_{\lambda} \quad=$ optics transmittance

$A \quad=$ pixel area

$g \quad=$ read-out electronics gain

$f \# \quad=$ optics f-number

$i_{\text {time }}=$ IR-camera integration time

Therefore, the experimental parameters to be controlled during the calibration procedure are the integration time, the optics $f$ number and other settings of the NIR camera (e.g., the gain of the read-out electronics which may be selected by the operator). Fixing these parameters for a certain interval of integral radiance, it is possible to determine the AIRF of the camera by using an extended reference source. The function (calibration curve) so obtained is then used to determine the values of integral radiance for reconstructing the radiant intensity map of the target.

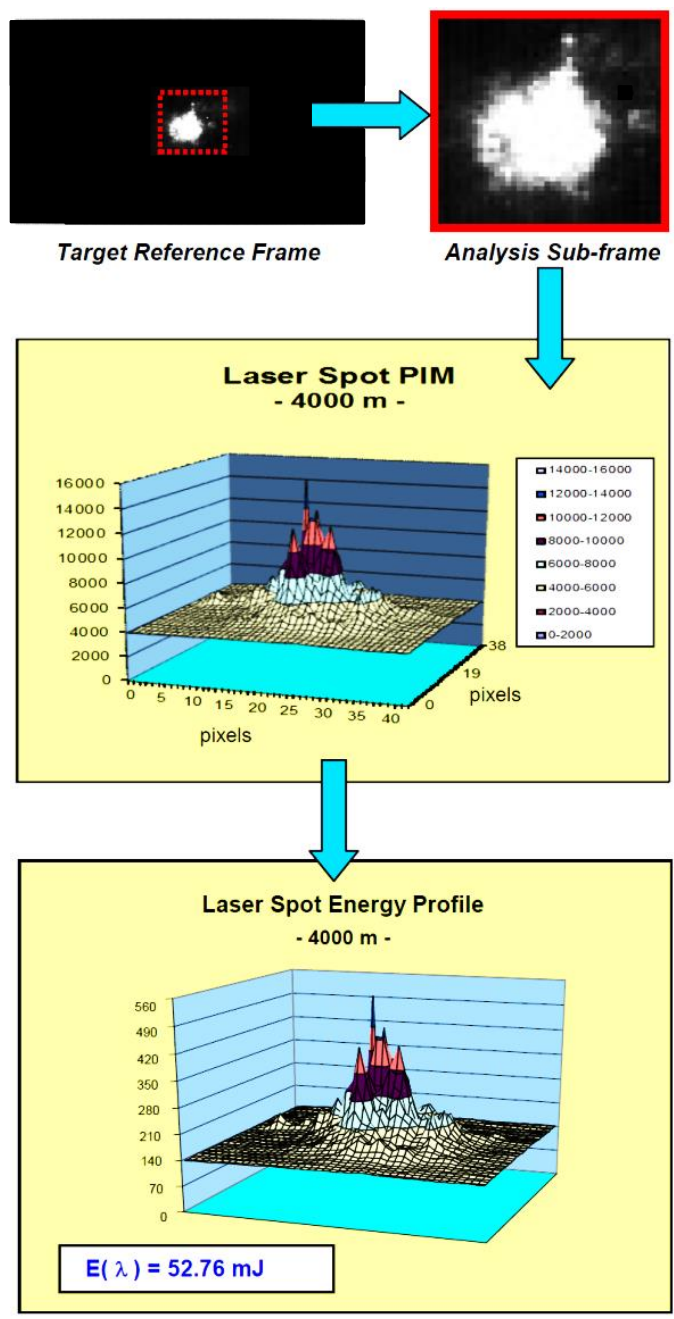

Fig. 4. EMT-1 (calibrated IR camera).

The EMT-1 calibration setup is shown in Fig. 5. 


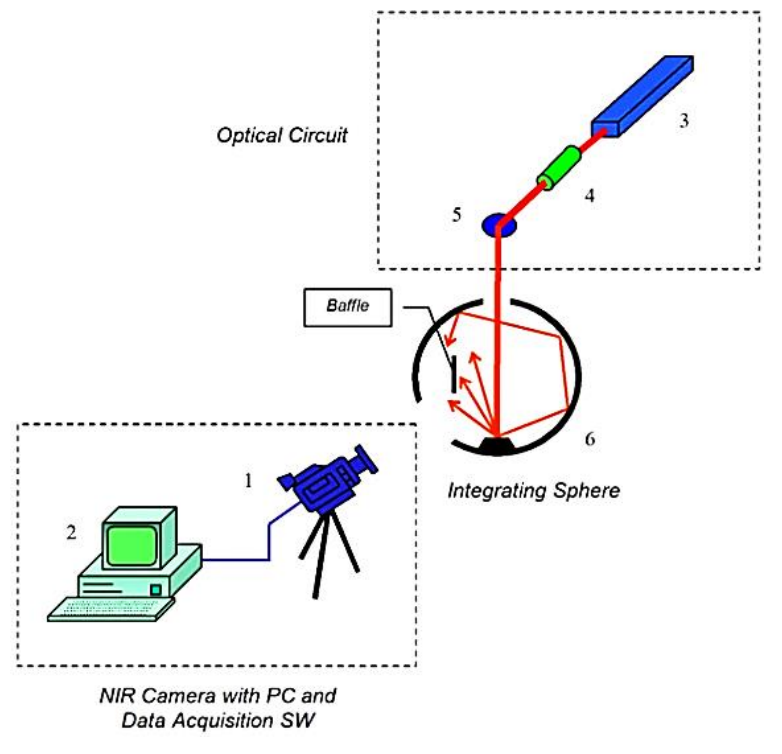

Fig. 5. IR-camera calibration layout for EMT-1.

Unlike EMT-1, no calibration is required for EMT-2 as an array of detectors performs direct measurements of the incident laser spot energy at specific locations on the target surface (Fig. 5).
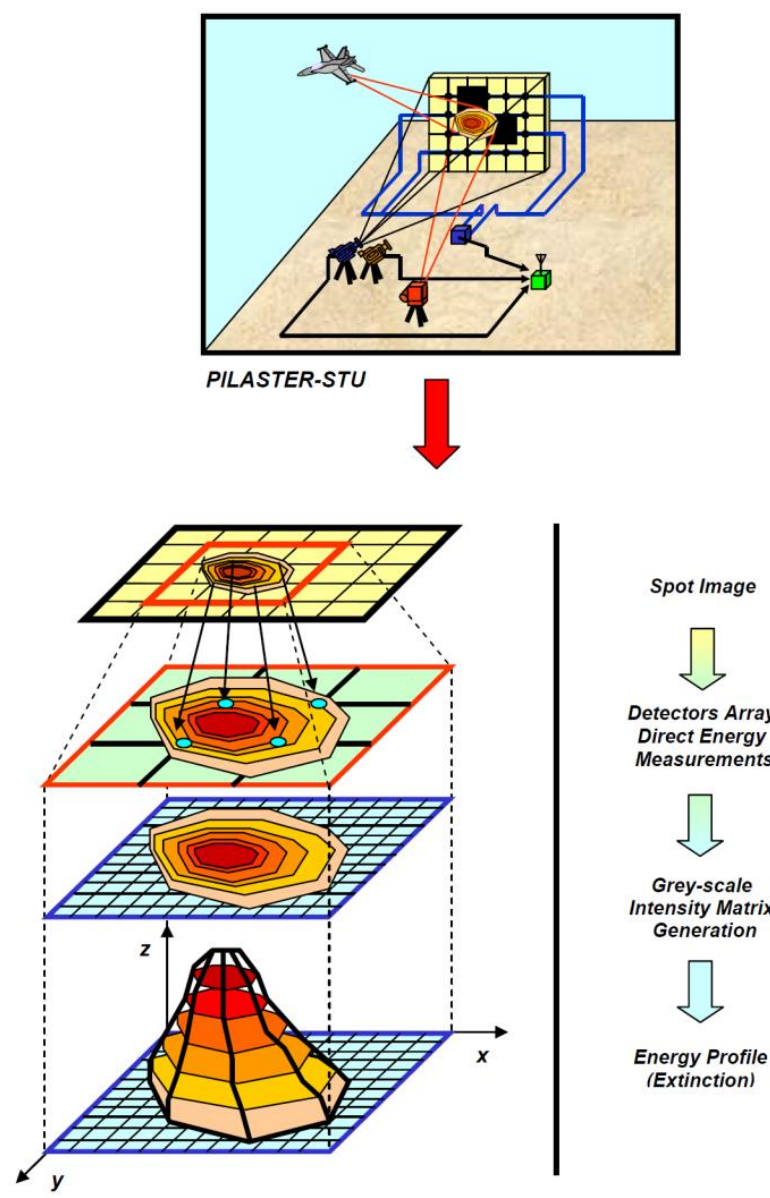
Direct Energy Measurements

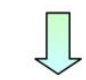

Grey-scale Intensity Matrix Generation

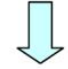

Energy Profile (Extinction)

Fig. 5. EMT-2 (non-calibrated IR camera).

In order to allow an optimal EMT-1/EMT-2 data retrieval both for real-time analysis and for post-processing of experimental and training mission data, some mathematical models were also developed and experimentally validated to calculate the optimal frame rate of the IR cameras. Additionally, a third technique (EMT-3) was developed for high Pulse Repetition Frequency (PRF) applications (beyond $10 \mathrm{kHz}$ ), where the IRcamera frame-grabbing performance is exceeded and EMT1/EMT-2 cannot be employed. One of the possible EMT-3 experimental arrangements is depicted in Fig. 7.

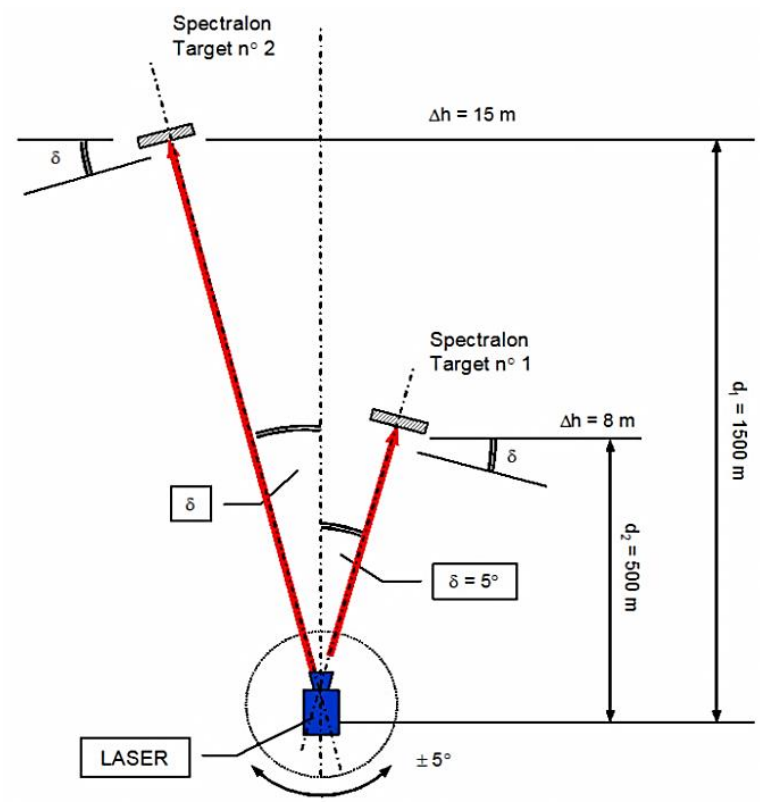

Fig. 6. EMT-3

The expression to determine atmospheric extinction $(\gamma)$ with EMT-3 is [1]:

$$
\gamma=\frac{1}{2 \Delta d} \cdot \ln \left[\left(\frac{V_{1}}{P_{O 1}} \cdot d_{1}^{2}\right) /\left(\frac{V_{2}}{P_{O 2}} \cdot d_{2}^{2}\right)\right]
$$

where:

$\Delta d \quad=\mathrm{d}_{1}-\mathrm{d}_{2}$

$V_{l} \quad=$ anodic voltage at receiver for the first target

$V_{2} \quad=$ anodic voltage at receiver for the second target

$P_{O 1} / P_{O 2}=$ emitted laser powers

More details about EMT-1, EMT-2 and EMT-3 are provided in $[1,12]$.

\section{TARGET FACILITIES AND INFRASTRUCTURE}

An overview of the PILASTER layout is given in Fig. 8, (MSU not shown). In particular, the following elements are depicted:

- $\quad$ FXDT and FRCT;

- Permanent STU;

- Hardened Sheltered STU (HSH);

- Electric Power Generator (EPG). 


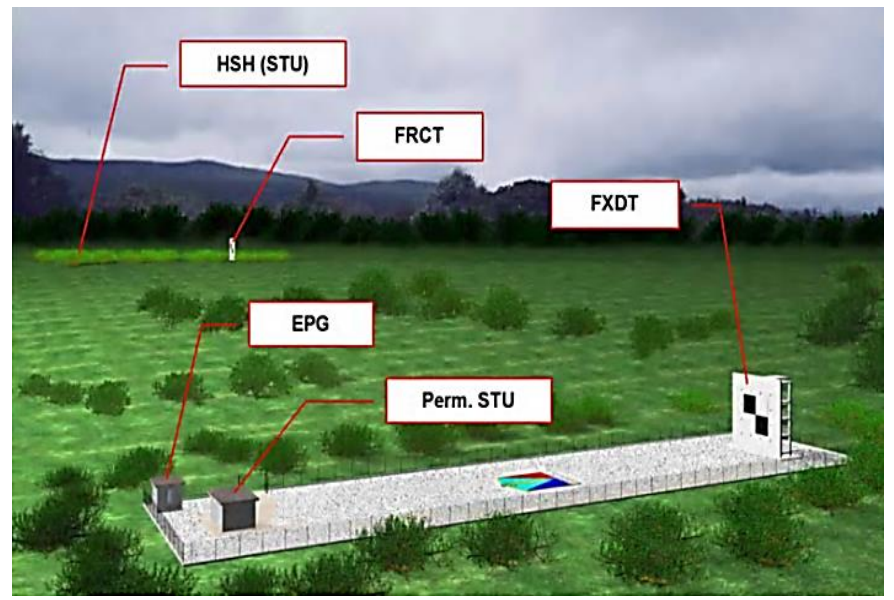

Fig. 8. Overview of the overall PILASTER layout.

The FXDT target is designed to perform geometrical and energy measures without LGW delivery, whereas the FRCT is designed to withstand multiple LGW hits. Therefore, this target is composed by a number of expendable and quickly replaceable modules, such as the high reflectance and well contrasted panels depicted in Fig. 9.
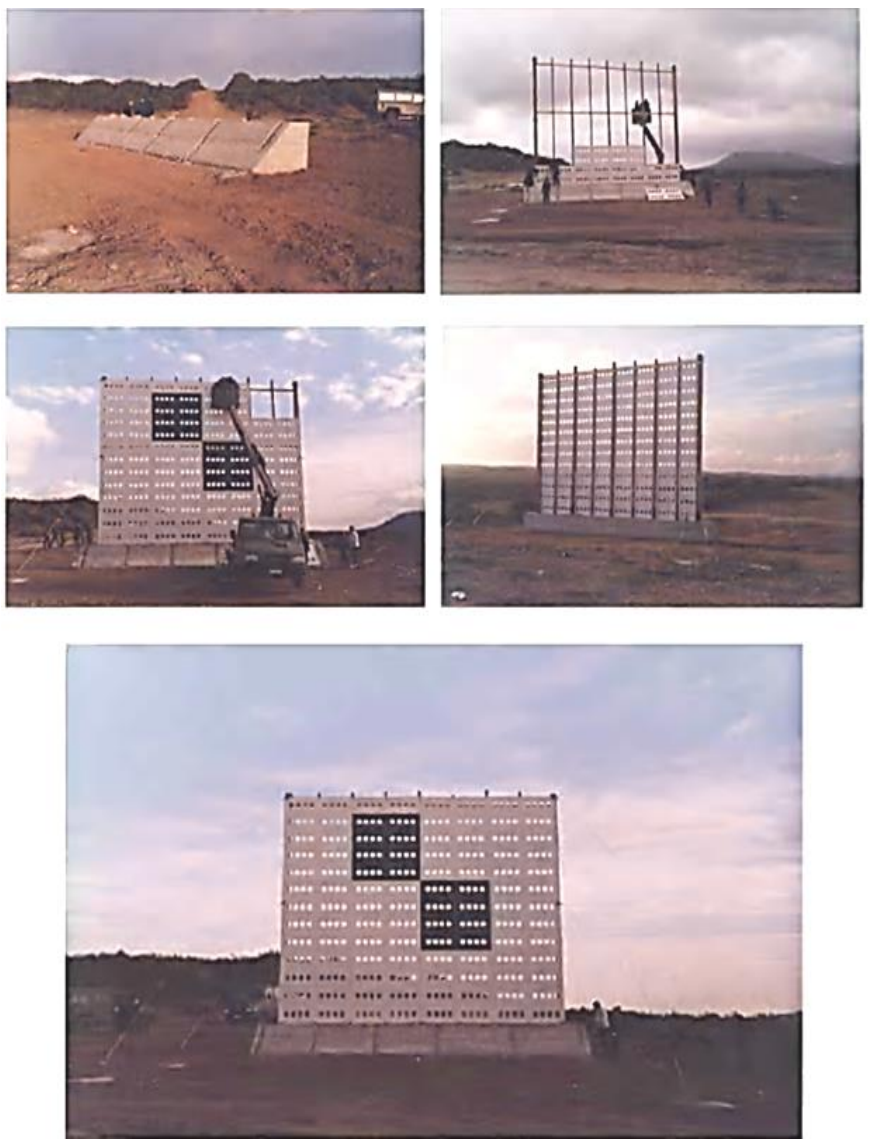

Fig. 9. FRCT Target.

The EPG unit supplies the STU at both FXDT and FRCT sites. Some details of the detachable FXDT modules are shown in Fig. 10.

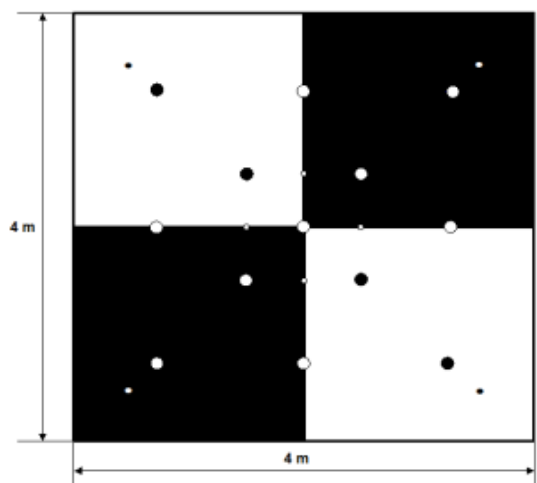

(a)

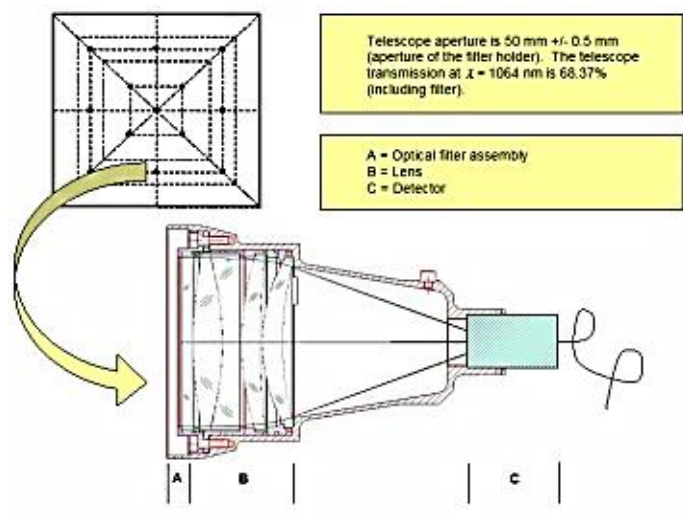

(b)

Fig. 10. FXDT panel features.

The supporting structure of the FXDT is about $15 \times 15$ meters, with a Reference Target Frame (RTF) area of about 8x8 meters. Resolution testing of avionics and ground FLIR systems can be performed by employing the target panel shown in Fig. 11. This panel is composed of a series of stripes and can be mechanically tilted both vertically and horizontally. Adequate coatings and calibrated thermocouples ensure that the stripes are highly contrasted both in the visible and infrared portions of the spectrum. Further calibration can be performed in-situ before training/experimental missions, by using the IR cameras in the STU subsystem.

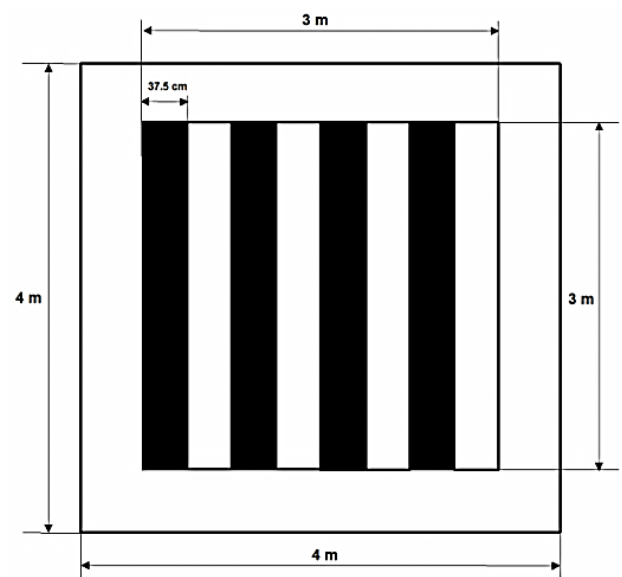

Fig. 11. High thermal contrast resolution panel. 


\section{Mission PlanNING AND ANALYSIS SOFTWARE}

Full-scale PILASTER operations require a number of software algorithms for mission planning and post-processing of STU sensor data recorded in real-time by the STU/MSU. In particular, analysis software includes:

- Operational planning software, consisting of the following elements:

- operational performance and flight profile calculation software;

- ground and airborne systems safety analysis software.

- Real-time operational/experimental mission analysis software (MSU).

- Post-mission data analysis software:

- data analysis software for training missions with real weapon delivery;

- data analysis software for experimental/training missions without weapon delivery.

The required mathematical models were developed and tested as part of the PILASTER development. A short overview of such models and of the software developed for mission planning and data analysis is given below.

\section{A. Operational planning software}

From a geometrical perspective, both the cooperative and selfdesignation mission profiles can be described as in Fig. 12.

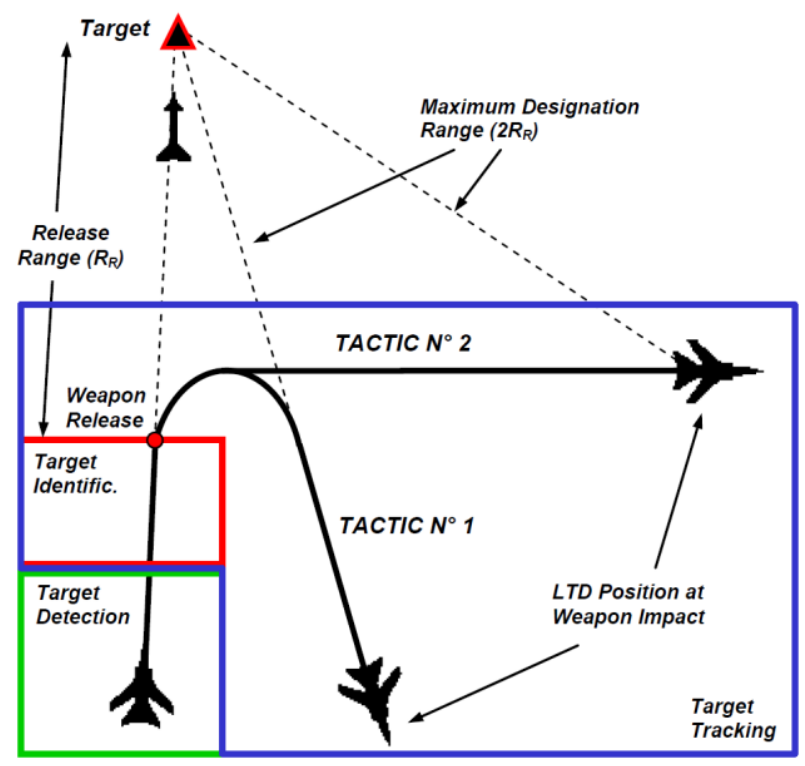

Fig. 12. Air-ground laser mission profiles.

Therefore, with reference to Fig. 13, the following form of the laser range equation can be used to determine the performance of a specific LTD/LGW combination [1]:

$$
I=\frac{4 \rho_{T} U A \cos \theta_{t} \cos \theta_{r} \cos \gamma_{R} \tau}{\pi^{2}\left(D_{L}+\alpha_{T} R_{T}\right)^{2} R_{R}{ }^{2}}
$$

where:

$U=$ transmitted energy

$\rho_{T} \quad=$ target reflectance
$A=$ laser spot area

$D_{L}=$ laser aperture diameter

$\alpha_{T}=$ laser beam divergence

$\tau=$ atmospheric transmittance

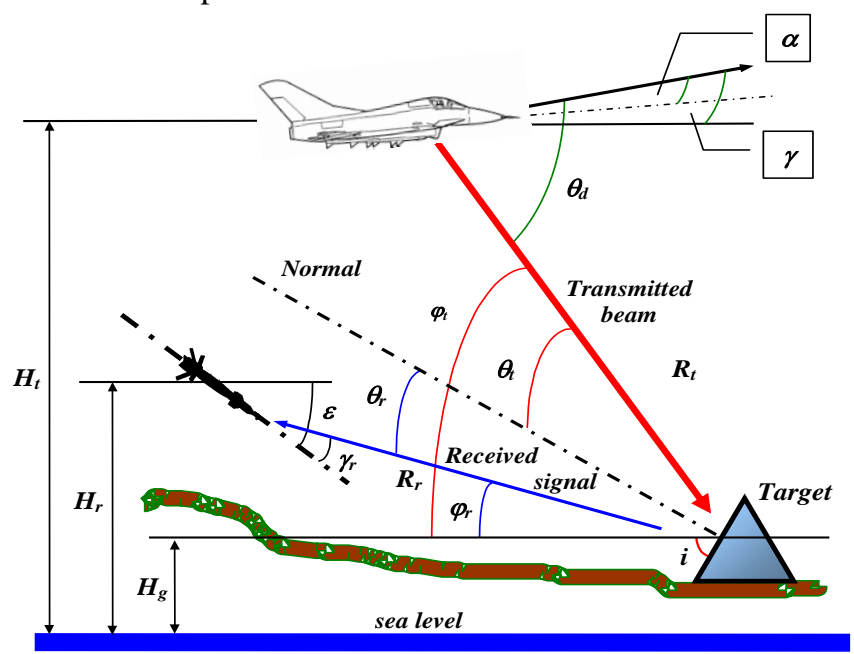

Fig. 13. Mission geometry for non-collocated designator and receiver.

Mathematical models of atmospheric transmittance, both for estimation of the operational performance and for safety assessment, were initially derived from the available literature and progressively refined by introducing appropriate correction parameters/functions during the PILASTER ground and flight test campaigns. In particular, the combined ElderStrong-Langer-Middleton (ESLM) model [13-15] was adopted as the original reference. An example of the ESLM transmittance models in the various infrared windows (i.e., molecular and aerosol absorption and scattering) are listed in Table 1 and 2. These models apply to horizontal propagation along a path length $(R)$ at sea level, with different values of atmospheric visibility $(V)$ and condensed water vapour contents $(w)$. In the rain case, the $\Delta x / \Delta t$ parameter represents the rainfall-rate in $\mathrm{mm} / \mathrm{hr}$. The complete model set used for PILASTER atmospheric propagation computation accounts also for non-linear effects (atmospheric turbulence, thermal blooming, bleaching, aerodynamic effects, etc.), that affect infrared laser propagation both at sea level and at different altitudes [1, 11]. Further models of fundamental importance are those relative to laser reflection from the targets. The PILASTER models account for both spectral reflectance and Bidirectional Reflectance Distribution Function (BRDF) of the employed materials and coatings. The validity and applicability of these models were experimentally verified during the PILASTER development performing the laboratory activities described in [1]. As an example, in order to determine the BRDF of various candidate materials and coatings for the FXDT, a Laser Scatterometer (LSM) was designed and implemented. With reference to Fig. 14, the LSM employed the following components:

1) Laser source.

2) Intensity and polarization control:
a) ND filters;
b) linear polarizer;
c) retardation plates. 
3) Sample.

4) Collimator, (5) Polarising filter (analyser) and (6) Detector.

7) Sample turn-table and (8) Receiver turn-table.

9) Light shield.

10) Energy/power meter, motion control unit and computer.

Laboratory BRDF measurements were performed with various incident angles $\left(\psi=0^{\circ}, 30^{\circ}, 45^{\circ}\right.$ and $\left.60^{\circ}\right)$ and both parallel $(P)$ and perpendicular $(S)$ polarization of the incident laser beam (con $\psi=0^{\circ}$ and $\left.45^{\circ}\right)$.

TABLE I. ATMOSPHERIC TRANSMITTANCE FOR HORIZONTAL ONE-WAy PathS AT MEAN SEA LEVEL

\begin{tabular}{|c|c|}
\hline Conditions & Transmittance \\
\hline $\begin{array}{c}\mathrm{V} \geq 6 \mathrm{~km} \\
w \geq w_{i}\end{array}$ & $k_{i}\left(\frac{w_{i}}{w}\right)^{\beta_{i}} \exp \left[-\frac{3.91}{V} R\left(\frac{\lambda_{i}}{0.55}\right)^{-(0.0057 \cdot V+1.025)}\right]$ \\
\hline $\begin{array}{c}\mathrm{V} \geq 6 \mathrm{~km} \\
w<w_{i}\end{array}$ & $\exp \left\{-R\left[A_{i} \sqrt{w_{t}}+\frac{3.91}{V}\left(\frac{\lambda_{i}}{0.55}\right)^{-(0.0057 \cdot V+1.025)}\right]\right\}$ \\
\hline $\begin{array}{c}\mathrm{V}<6 \mathrm{~km} \\
w \geq w_{i}\end{array}$ & $k_{i}\left(\frac{w_{i}}{w}\right)^{\beta_{i}} \exp \left[-\frac{3.91}{V} R\left(\frac{\lambda_{i}}{0.55}\right)^{-0.585 \sqrt[3]{V}}\right]$ \\
\hline $\begin{array}{c}\mathrm{V}<6 \mathrm{~km} \\
w<w_{i}\end{array}$ & $\exp \left\{-R\left[A_{i} \sqrt{w_{t}}+\frac{3.91}{V}\left(\frac{\lambda_{i}}{0.55}\right)^{-0.585 \sqrt[3]{V}}\right]\right\}$ \\
\hline $\begin{array}{c}\text { Rain } \\
w \geq w_{i}\end{array}$ & $k_{i}\left(\frac{w_{i}}{w}\right)^{\beta_{i}} \exp \left[-0.365 R\left(\frac{\Delta x}{\Delta t}\right)^{0.63}\right]$ \\
\hline $\begin{array}{c}\text { Rain } \\
w<w_{i}\end{array}$ & $\exp \left\{-A_{i} \sqrt{w}\left[-0.365 R\left(\frac{\Delta x}{\Delta t}\right)^{0.63}\right]\right\}$ \\
\hline
\end{tabular}

TABLE II. COEFFICIENTS FOR THE ATMOSPHERIC TRANSMITTANCE

\begin{tabular}{|c|c|c|c|c|}
\hline Window & $\boldsymbol{A}_{\boldsymbol{i}}$ & $\boldsymbol{k}_{\boldsymbol{i}}$ & $\boldsymbol{\beta}_{\boldsymbol{i}}$ & $\boldsymbol{w}_{\boldsymbol{i}}$ \\
\hline $\mathbf{I}$ & 0.0305 & 0.800 & 0.112 & 54 \\
\hline II & 0.0363 & 0.765 & 0.134 & 54 \\
\hline III & 0.1303 & 0.830 & 0.093 & 2.0 \\
\hline IV & 0.211 & 0.802 & 0.111 & 1.1 \\
\hline V & 0.350 & 0.814 & 0.1035 & 0.35 \\
\hline VI & 0.373 & 0.827 & 0.095 & 0.26 \\
\hline VII & 0.598 & 0.784 & 0.122 & 0.165 \\
\hline
\end{tabular}

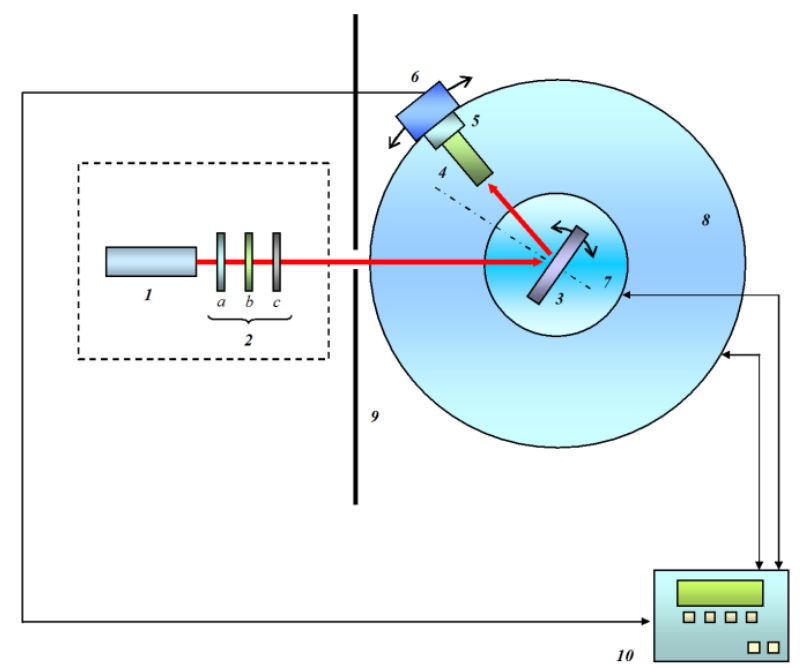

Fig. 15. Laser scatterometer developed for BRDF measurements.

Some BRDF measurement results relative to a diffuse reflector (dominating Lambertian reflection components) are shown in Fig. 16.
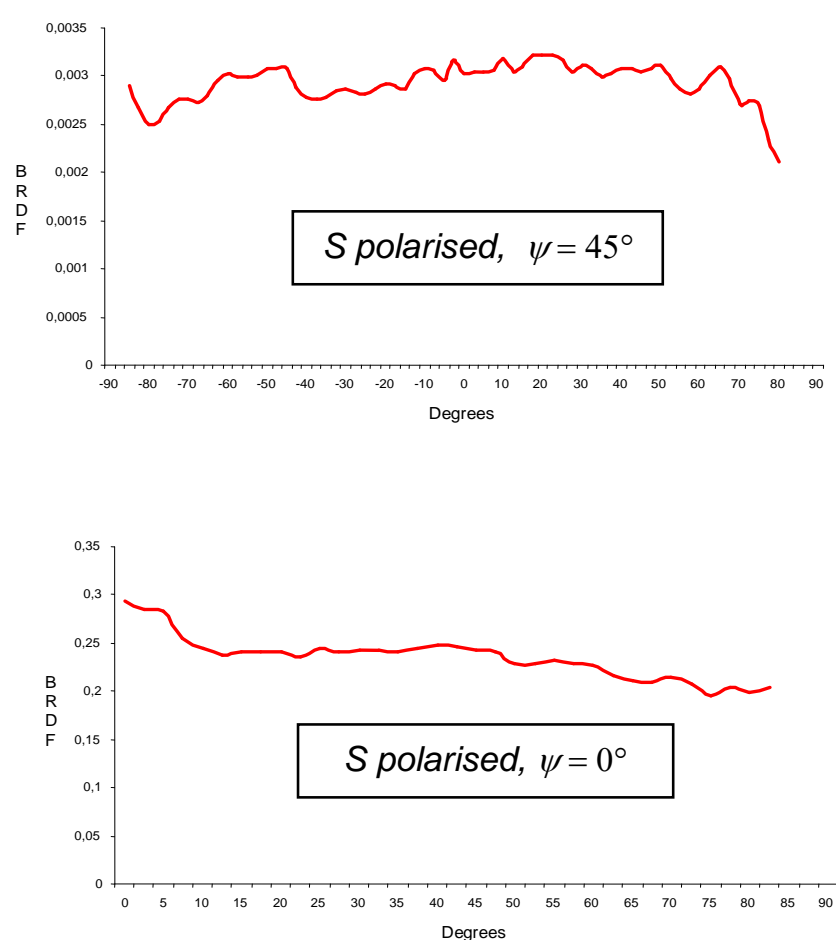

Fig. 16. BRDF for predominantly diffuse reflection surface.

For comparison, Fig. 17 shows the BRDF of a highly specular reflector material. 

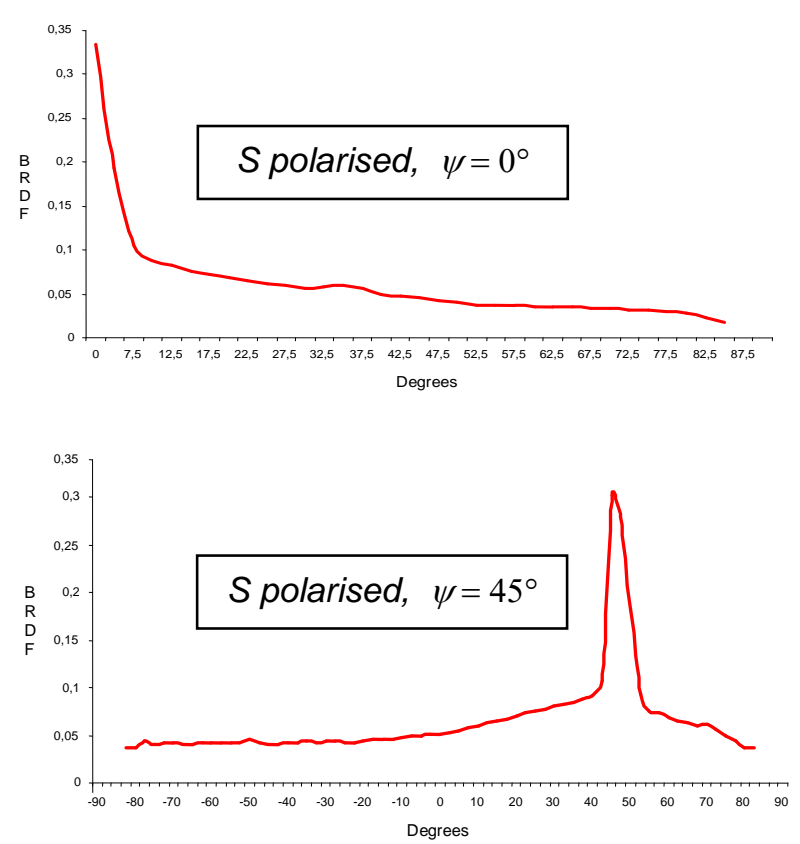

Fig. 17. BRDF of predominantly specular reflection surface.

Additional laboratory test activities were required to experimentally characterise the EMTs to be employed in the PILASTER system, to select the STU sensors and to measure some essential LGW parameters. As an example, Fig. 17 shows the laboratory layout adopted for measuring the Minimum Detectable Power Density (MDPD) of some LGW seekers and Fig. 18 shows a detail of the target simulator instrumentation.

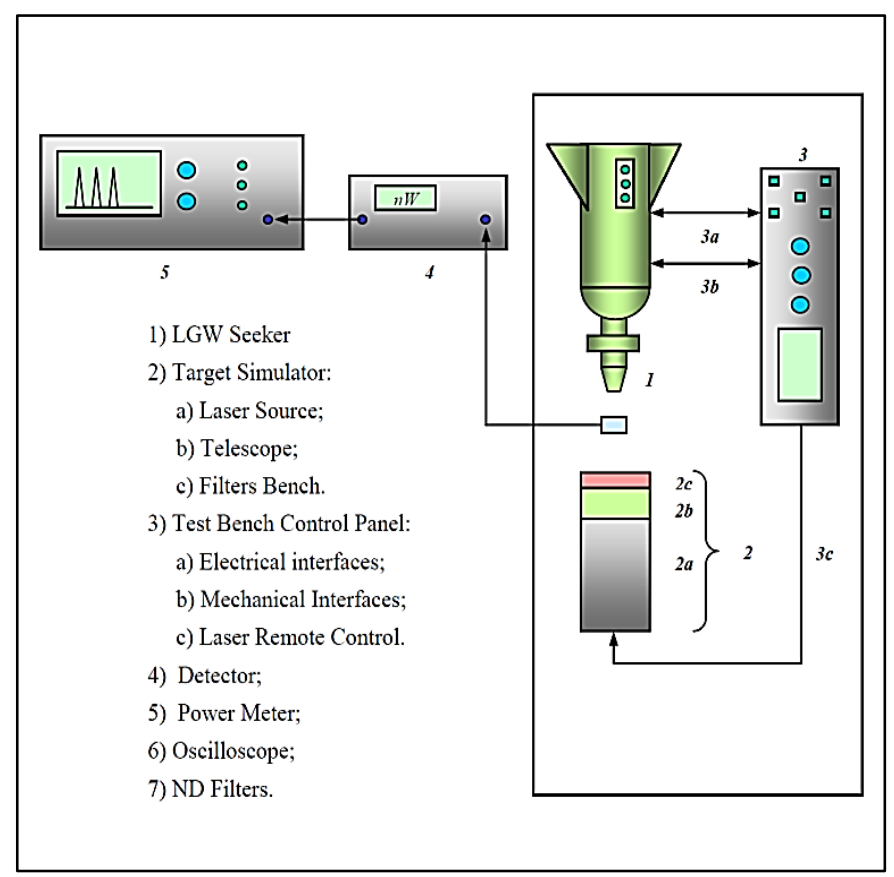

Fig. 18. MDPD measurement layout.

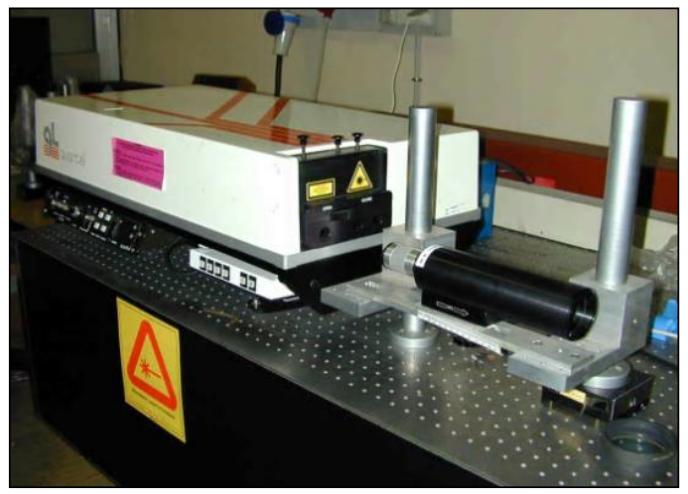

Fig. 18. Target simulator detail.

Fig. 19 shows some simulation results obtained applying the PILASTER range performance calculation algorithms to an LTD/LTW combination with the following characteristics:

- Aperture laser beam diameter: $60 \mathrm{~mm}$

- Beam divergence: $0.2 \mathrm{mrad}$

- Wavelength: $1064 \mathrm{~nm}$

- Peak energy: $100 \mathrm{~mJ}$

- Pulse duration: $10^{-8} \mathrm{sec}$

- Seeker field of view: 18 degrees

- Seeker MDPD: $3 \mu \mathrm{W} / \mathrm{m}^{2}$

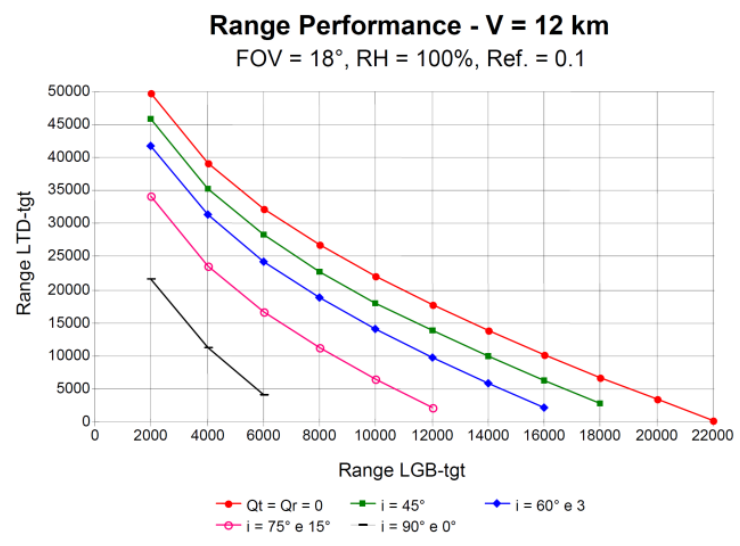

(a)

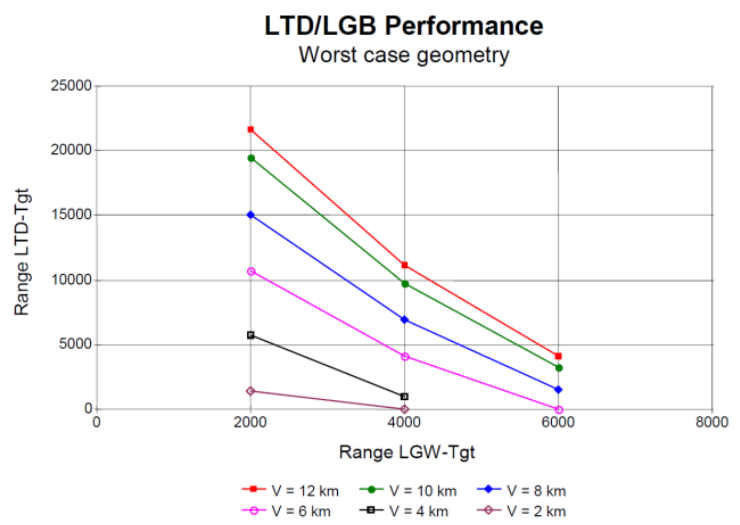

(b)

Fig. 19. Range performance calculation results 
Results in Fig. 19(a) refer to atmospheric visibility values of $12 \mathrm{~km}$ with different geometries (corresponding to various aircraft and armament. dynamic conditions), and a target reflectance of $10 \%$. Fig. 19(b) is obtained for the same conditions but setting all geometric parameters to the worst case. Since laser operating in the near infrared present potential risks for the naked human eye (flight crew, ground operators and other people on the ground), it was necessary to develop analytical models and software tools allowing the determination of the risk areas related to both ground and airborne systems. For air-to-ground laser illumination, some novel algorithms were developed for eye-safety analysis which, based on minimum input data (i.e., laser system characteristics, target dimensions, and test range dimensions or position of unprotected personnel on the ground) are able to determine:

- the required clearance area of the test range and the minimum altitude profile of the aircraft for airborne systems;

- the test range area in which it is safe to operate groundbased laser systems.

With reference to Fig. 20, starting from Nominal Ocular Hazard Distance (NOHD) and Ocular Hazard Distance (OHD) calculated in line with the applicable NATO STANAGs and national standards [16-23], the algorithm shown in Fig. 21 was developed to recursively assess the safety of any point located in the test range and for variable lasing times, as a function of the aircraft flight dynamics $[1,11]$.

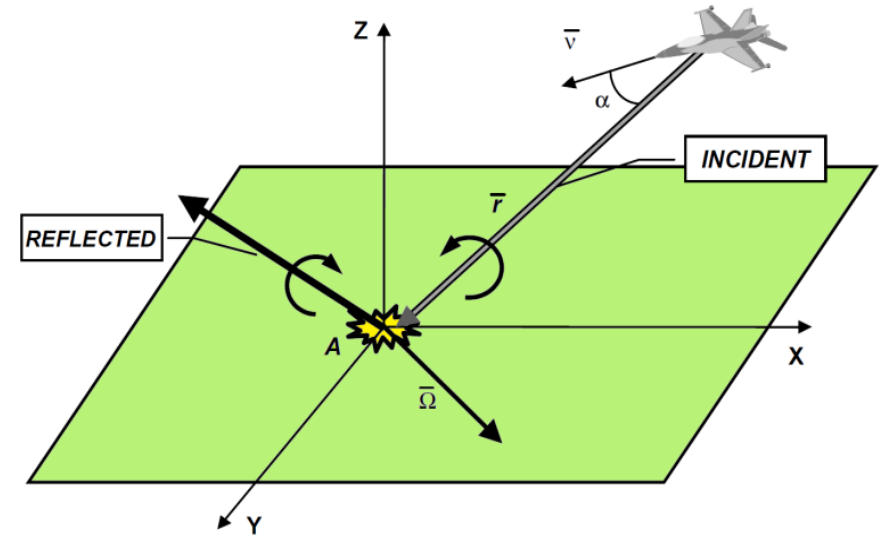

Fig. 20. Safety area geometry.

The developed algorithms also allow to perform an inverse analysis, which is to calculate flight profile restriction that guarantee the specified safety levels in the designated test range area. As an example, the flight profile restrictions for safe operations of the LTD/LTW combination introduced above and applying to a test range circular area of $5 \mathrm{~km}$ in diameter are shown in Fig. 22. Concerning eye-safety of ground laser systems, suitable algorithms were also developed to determine G-LTD Safe Positioning Areas (SPA) in range/bearing with respect to the target surface normal, given specific target dimensions and terrain elevation data. An example of this analysis is shown in Fig. 23, where the ground positioning restrictions for a G-LTD system (ELOP-PLD) are shown as a function of target dimensions and for two distinct operational procedures.

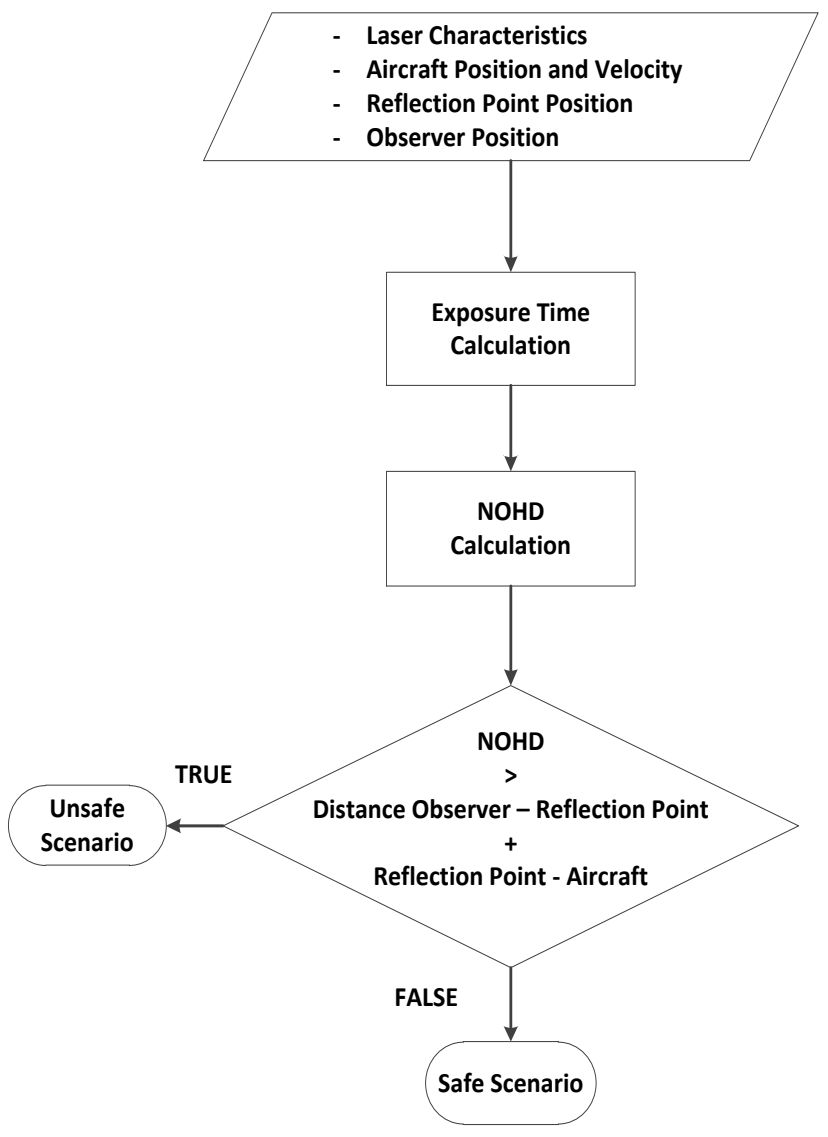

Fig. 21. Eye-safety analysis algorithm kernel.

In particular, procedure 1 refers to the case of LSO real-time laser system monitoring and remote control (MSU instrumentation) and procedure 2 refers to the absence of realtime MSU/LSO operations. The angle $\varphi$ shown in Fig. 23 is a function of the G-LTD vertical and lateral displacement with respect to the target surface as detailed in $[1,11]$.

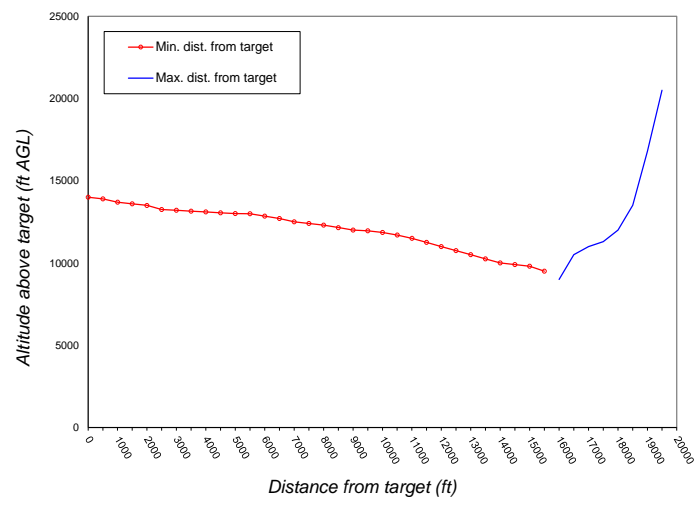

Fig. 22. Altitude restrictions for eye-safety. 


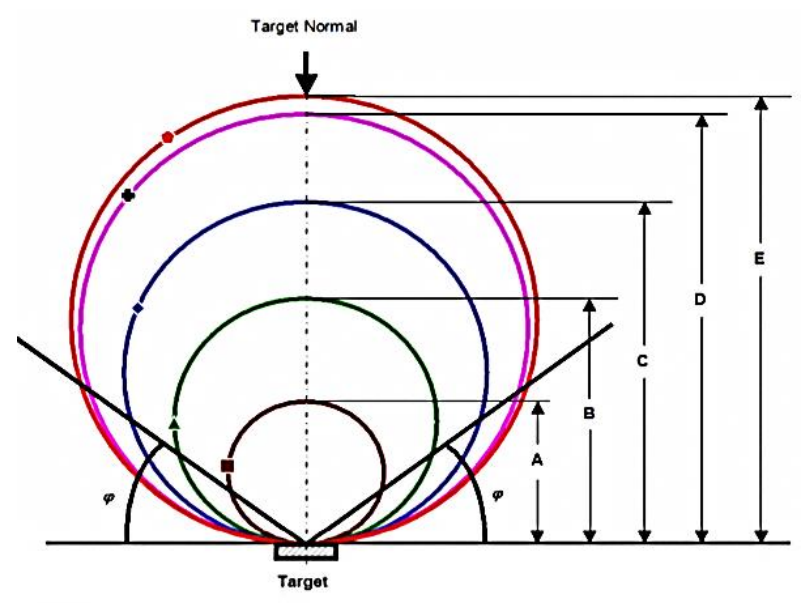

Symbols:

- Target $10 \times 10 \mathrm{~m}$

——— Target $9.76 \times 7.92 \mathrm{~m}$

—— Target $7.32 \times 7.32 \mathrm{~m}$

- $\mathbf{A}$ - Target $4.88 \times 4.88 \mathrm{~m}$

-日一 Target $2.44 \times 2.44 \mathrm{~m}$

\begin{tabular}{|c|c|c|c|}
\hline \multicolumn{2}{|c|}{ Procedure 1 } & \multicolumn{2}{c|}{ Procedure 2 } \\
\hline A & $500 \mathrm{~m}$ & A & $3500 \mathrm{~m}$ \\
\hline B & $1000 \mathrm{~m}$ & B & $7200 \mathrm{~m}$ \\
\hline C & $1550 \mathrm{~m}$ & C & $10900 \mathrm{~m}$ \\
\hline D & $2050 \mathrm{~m}$ & D & $14600 \mathrm{~m}$ \\
\hline E & $2100 \mathrm{~m}$ & E & $15000 \mathrm{~m}$ \\
\hline
\end{tabular}

Fig. 23. Calculated safe positioning area of the ELOP-PLD ground laser.

The PILASTER mission planning and data analysis software was developed as a comprehensive tool incorporating all system performance and safety calculation algorithms described above, allowing both pre-mission and post-mission analysis of the relevant system performance and safety aspects in the relevant flight/ground testing and training operational tasks. Some of the main interfaces of this software tool are depicted in Fig. 24.

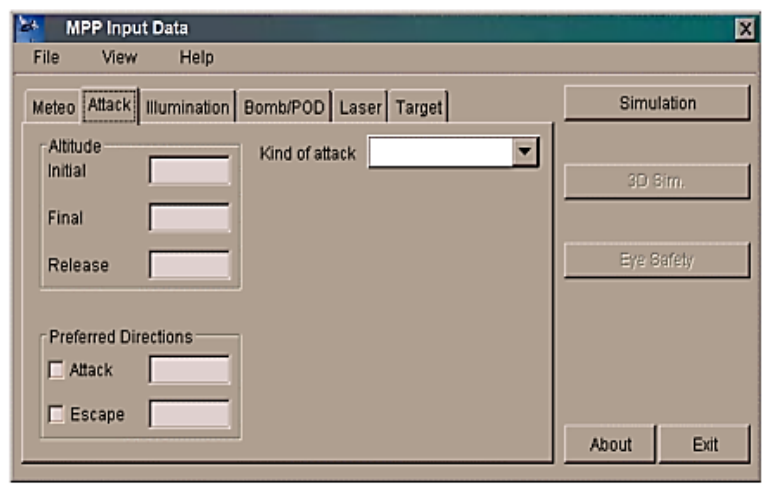

(a)

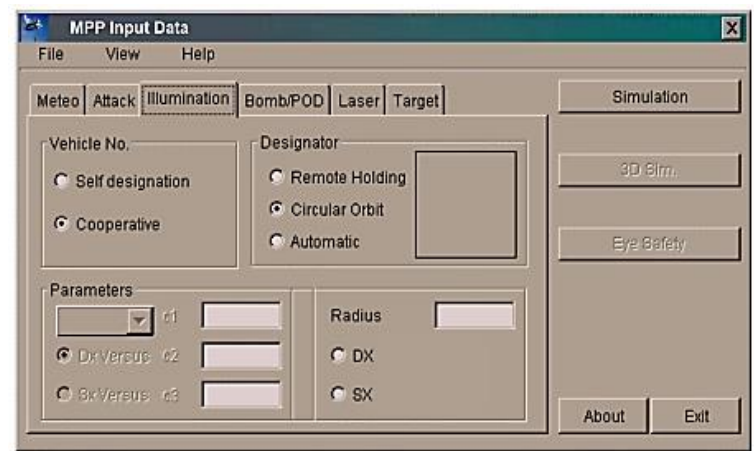

(b)

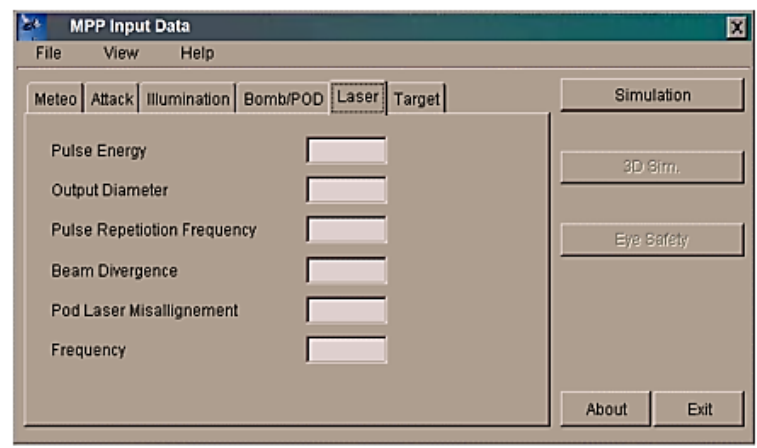

(c)

Fig. 24. Simulation software input interfaces.

Some output interfaces are shown in Fig. 25. In particular horizontal and vertical profiles of the aircraft/LGW, the power levels required for seeker activation and the flight restriction applying to eye-safe operations are represented.

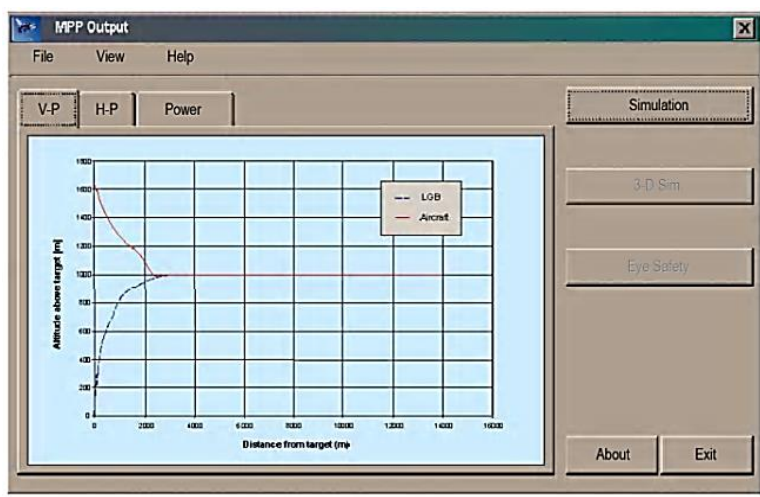

(a)

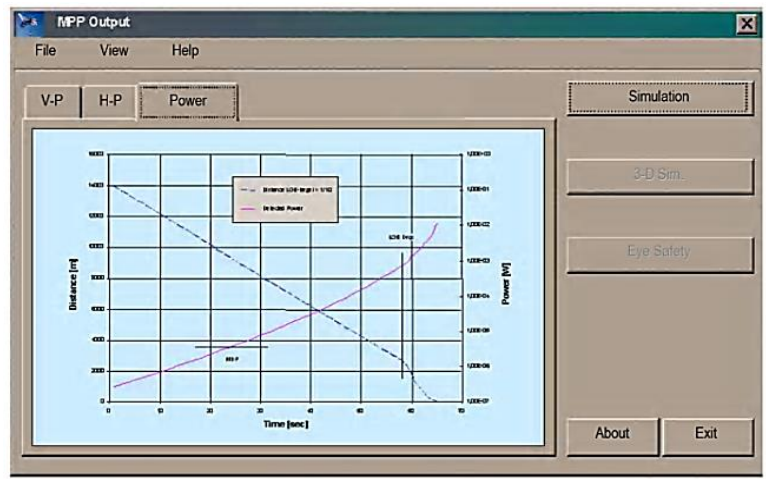

(b) 


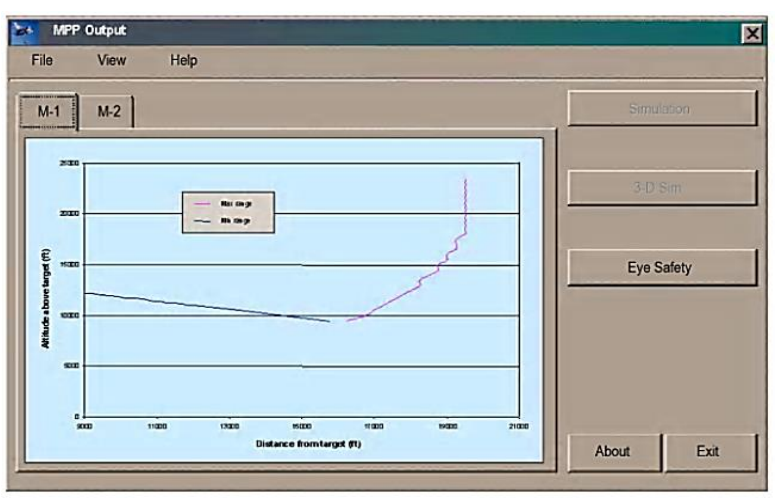

(c)

Fig. 25. Output interfaces of the simulation software.

As depicted in Fig. 26, a 3D rendering tool is also available to display the aircraft and LGW (both real and virtual delivery) flight profiles.
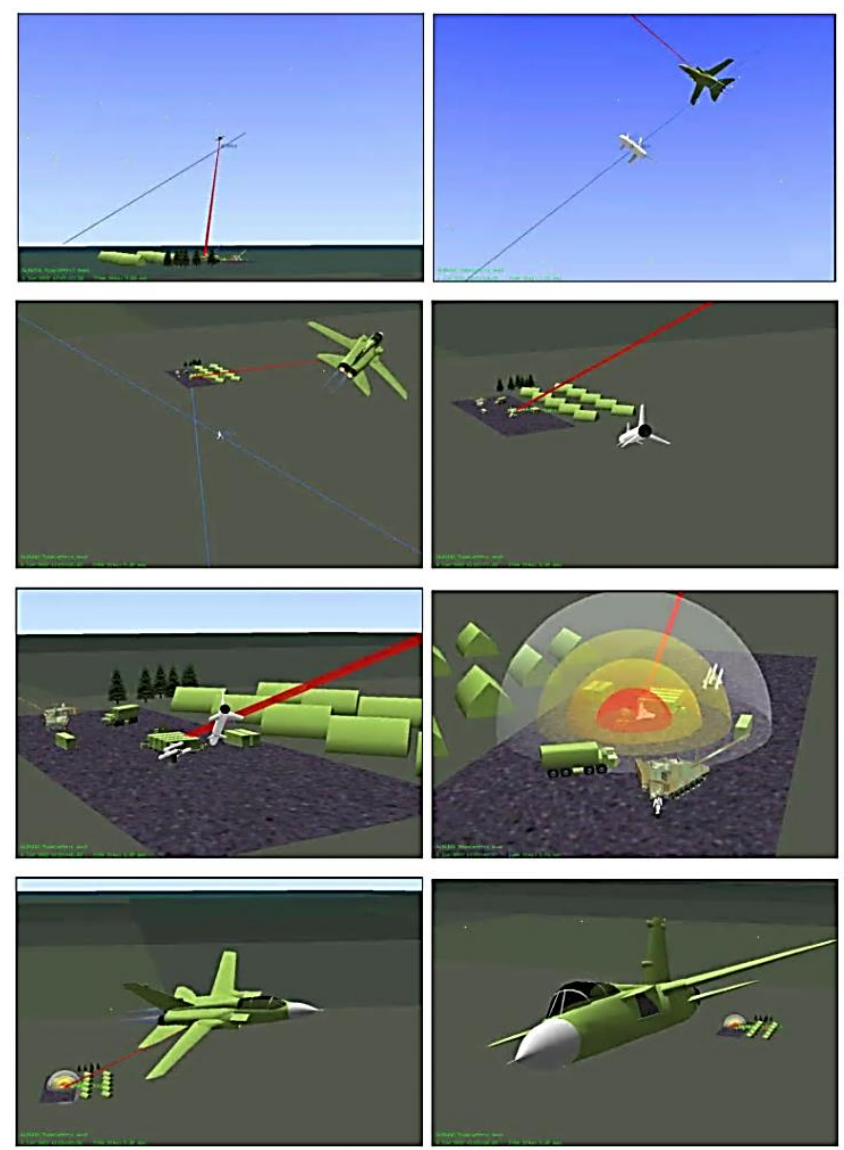

Fig. 26. 3D Simulation of the LTD/LGB.

This software tool is available both for test/training mission planning and for post-mission data analysis. Additionally, the tool can be also used for planning real flight/ground missions within the theatre of operations.

\section{REAL TIME AND POST-Mission ANALYSIS SOFTWARE}

A dedicated Digital Image Analysis (DIA) software tool was developed in an Image-Pro Plus ${ }^{T M}$ environment for real-time mission data analysis in the PILASTER MSU. This software enables a real-time computation and visualisation of the energy and geometric data relative to the laser spots observed by the IR cameras on the various target surfaces. In particular, the following data are provided:

- instantaneous position of the spot geometric centroid

- instantaneous position of the spot energy centroid

- geometric deviation (instantaneous and average distance between geometric centroid and aim point)

- $\quad$ energy deviation (instantaneous and average distance between the energy centroid and the aiming point)

- energy intensity on the target (instantaneous and average)

Some examples of the images displayed and recorded at the MSU are shown in Fig. 27. In particular, the figure depicts a slightly distorted (a), severely distorted (b) and fragmented (c) laser spot (emitted laser beam was a Gaussian beam with $87 \%$ correlation at the aperture). Dedicated interpolation algorithms were also developed to assure the centroid determination even in the rare case of fragmented spots, therefore preventing discontinuities in the data gathering process.

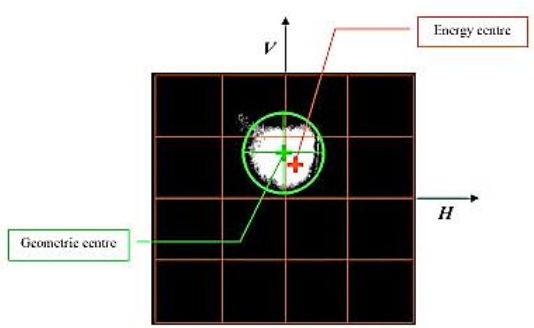

(a)

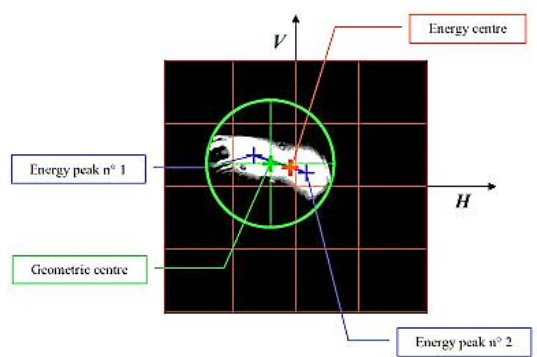

(b)

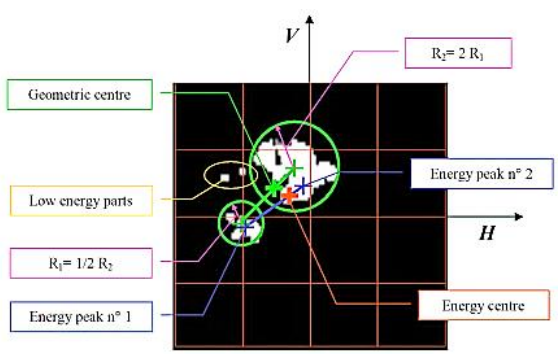

(c)

Fig. 27. Moderate distortion (a), severe distortion (b) and fragmented spot (c). 
The post-mission analysis software enables a more detailed examination of all data gathered during the operational training/experimental missions. In particular, statistics for both energy and geometric pointing accuracy are determined, including average error, standard deviation, etc. With reference to Fig. 28, the following Spot Distortion Parameters (SDP) are adopted for the laser spot characterisation:

$$
\begin{gathered}
Q_{S}=\frac{R}{R_{1}} \\
Q_{D e}=1-\frac{d_{g e}}{R_{1}} \\
Q_{D g}=\frac{R_{2}}{R_{1}}
\end{gathered}
$$

where $R$ is the expected radius of the laser spot at the distance $d$, given by:

$$
R=d \cdot \tan \Phi_{95 \%}+a
$$

and $a$ is the output diameter of the laser beam and $\Phi_{95 \%}$ is the beam divergence at $95 \%$ of total energy, given by:

$$
\Phi_{95 \%}=\Phi_{1 / e} \cdot \sqrt{\frac{\ln (1-0.95)}{\ln (1-0.632)}}
$$

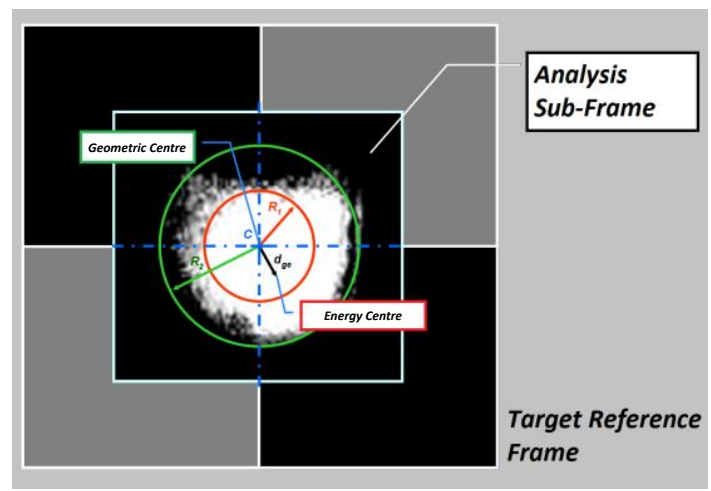

Fig. 28. Laser spot profile analysis.

The parameter $Q_{S}$ accounts for the spot spreading, $Q_{D e}$ is associated with the energy profile distribution, and $Q_{D g}$ characterises the geometric distortion of the laser spot. The SDP parameters equal to 1 for a Gaussian beam (ideal case) and tend to 0 with increasing deviation from the ideal Gaussian case. Additionally, atmospheric transmittance is calculated at the MSU by comparing the measured incident energy on the target with the energy transmitted by the laser system in use [1].

\section{EXPERIMENTAL RESULTS}

Ground and flight experiments were performed during the PILASTER development activities. These included NIR laser beam atmospheric propagation measurements, LTD and /LRF pointing accuracy tests, systems harmonisation and performance evaluation trials of the STU and DGPS components of the PILASTER system. A ditailed discussion about the ground experimental activities performed at two different NIR laser wavelengths ( $\lambda=1064 \mathrm{~nm}$ and $\lambda=1540 \mathrm{~nm})$ to develop correction fnctions for the ESLM model is provided in [1, 12]. As a result of these activities a Laser Propagation Database (LPD) has been created and it is being progressively refined based data collected at PILASTER during a test and training missions with a variety of tactical laser systems in a comprehensive range of weather conditions [1]. As an example of the aiming accuracy measurements, Fig. 29 shows results relative to the energy and geometric pointing errors of the ELOP-PLD system.

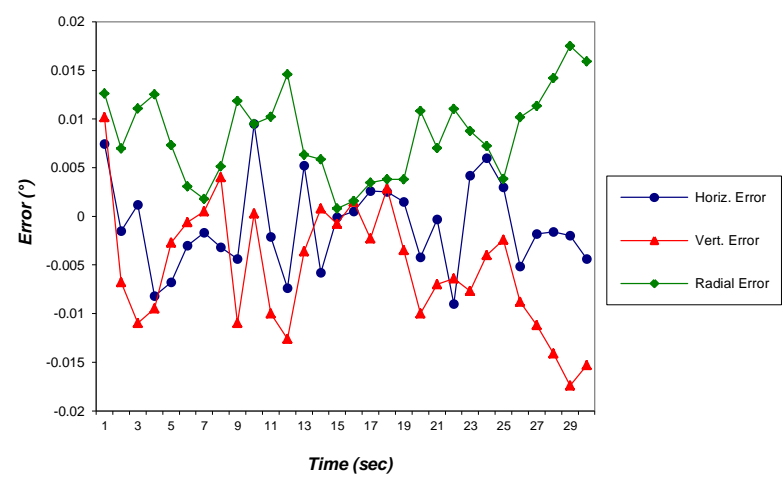

(a)

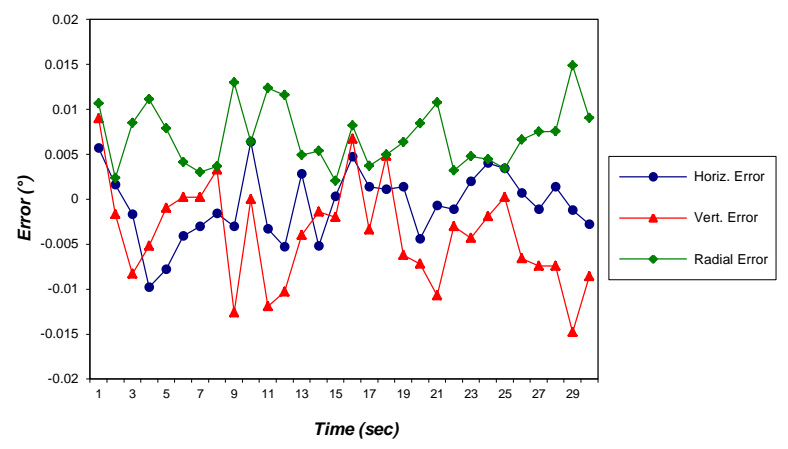

(b)

Fig. 29. ELOP-PLD pointing accuracy measurements.

Fig. 30 shows the difference between the geometric and energy pointing errors.

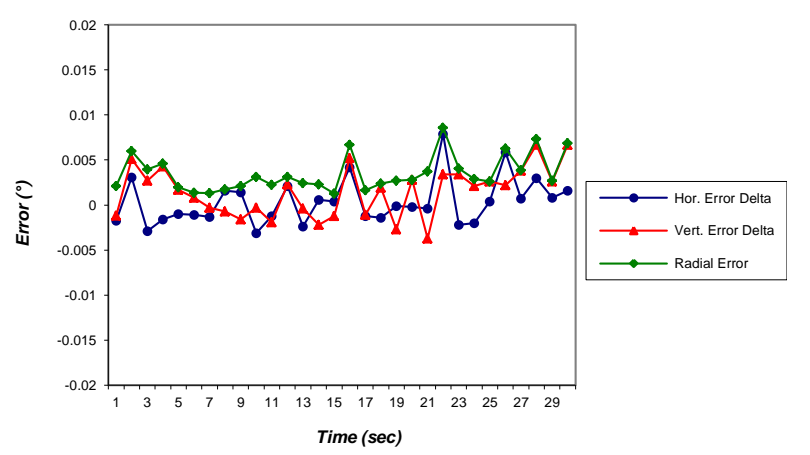

Fig. 30. ELOP PLD geometric vs. energy pointing errors. 
Results of the spot spreading measurements (average $2 R_{l}$ values) for the ELOP-PLD system are shown in Fig. 31, together with the calculated 1/e and 95\%-energy spot diameters. Although in certain cases the measured spot diameter (average of 150-200 measurements) was less that the calculated 95\%-energy spot diameter, the average data showed that the spot spreading was much more significant at greater slant-ranges.

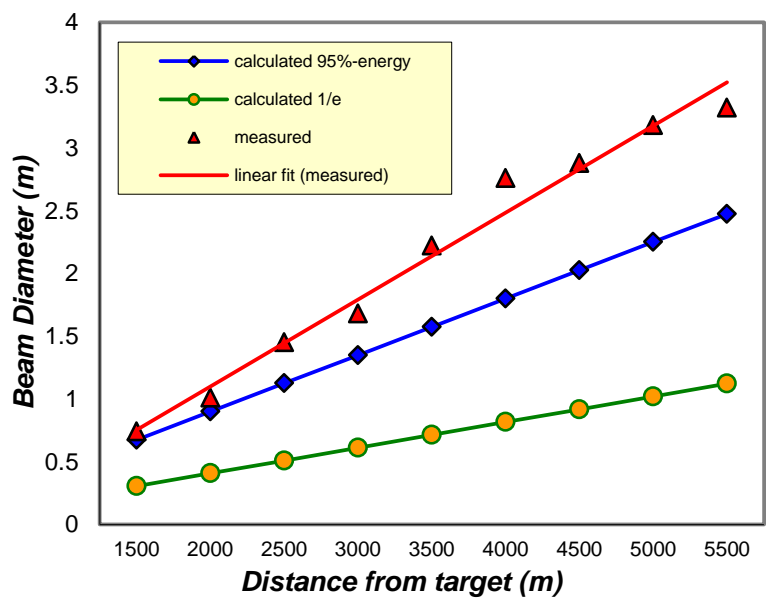

Fig. 31. ELOP-PLD calculated and measured spot diameter as a function of slant-range for normal incidence.

Furthermore, it was observed that also the SDP parameters increased significantly their values at increasing slat-ranges. The average SPD values and their variations during measurements performed with the ELOP-PLD $(\lambda=1064 \mathrm{~nm})$ at $\mathrm{SR}=1500 \mathrm{~m}, 3.5 \mathrm{~km}$ and $5.5 \mathrm{~km}$ are listed in Table III.

TABLE III. SPD PARAMETERS RELATIVE TO THE ELOP-PLD SPOT DISTORTION MEASUREMENTS.

\begin{tabular}{|c|c|c|c|c|c|c|}
\hline \multirow{2}{*}{$S P D$} & \multicolumn{2}{|c|}{$1500 \mathrm{~m}$} & \multicolumn{2}{c|}{$3.5 \mathrm{~km}$} & \multicolumn{2}{c|}{$5.5 \mathrm{~km}$} \\
\cline { 2 - 7 } & $\mu$ & $\sigma$ & $\mu$ & $\sigma$ & $\mu$ & $\sigma$ \\
\hline$Q_{S}$ & 0.8455 & 0.1350 & 0.8381 & 0.1799 & 0.6860 & 0.2830 \\
\hline$Q_{d e}$ & 0.8329 & 0.0913 & 0.7184 & 0.1575 & 0.6119 & 0.1837 \\
\hline$Q_{d g}$ & 0.7275 & 0.1289 & 0.6930 & 0.1340 & 0.6607 & 0.1723 \\
\hline
\end{tabular}

With increasing slant-range all SPD parameters were characterised by a progressive reduction of their mean values and greater dispersions. Therefore, although the exact nature of the correlation existing between the various SPD parameters has not been identified yet, an additional parameter has been introduced in order to characterise the overall laser spot quality [1]:

$$
Q=\frac{R+R_{1}+R_{2}-d_{g e}}{3 R_{1}}
$$

Obviously, as all the SPD parameters vary between 0 and 1 , also the $Q$ parameter varies between 0 and 1 (ideal Gaussian case). As an example, the average values of the $Q$ parameter calculated for the ELOP-PLD system $(\lambda=1064 \mathrm{~nm})$ during the PILASTER ground test campaign are the following:

- $Q=0.8020$ for $\mathrm{SR}=1500 \mathrm{~m}$;

- $Q=0.7498$ for $\mathrm{SR}=3500 \mathrm{~m}$;

- $Q=0.6529$ for $\mathrm{SR}=5500 \mathrm{~m}$.

Fig. 32 shows the mission profile of an airborne laser system. The various dive manoeuvres are depicted, with grazing angles between $20^{\circ}$ and $50^{\circ}$. The illuminated target is positioned in $(0,0)$. The red line depicts the lower limit for the safe activation of the laser system, to guarantee eye-safety.

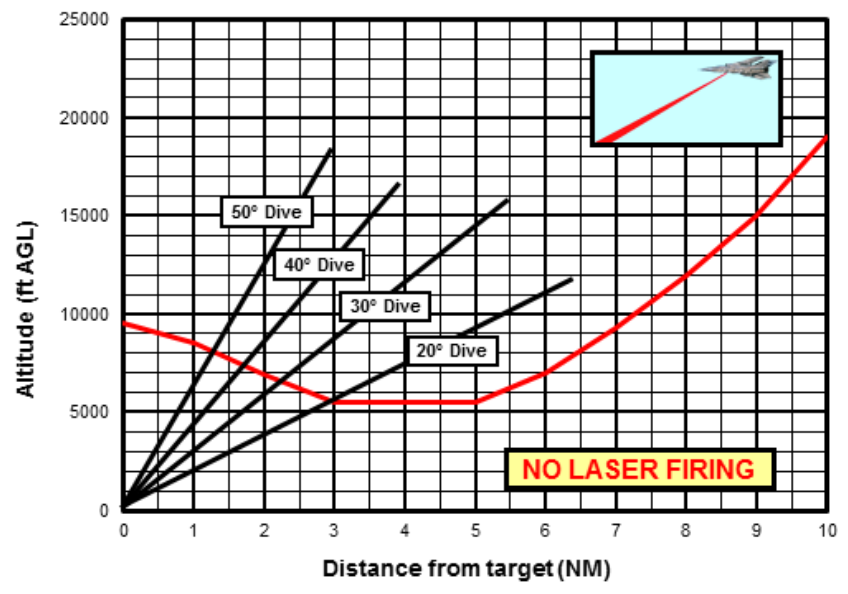

Fig. 32. Dive manoeuvre envelopes.

Experimental data collected during the manoeuvres depicted in Fig. 32 are represented in Fig. 33. In particular, the variation between the extinction coefficient $\left(\gamma_{\text {atm }}{ }^{H}\right)$ and the one relative to the mean sea level $\left(\gamma_{a t m}\right)$ are depicted as a function of altitude and grazing angle.

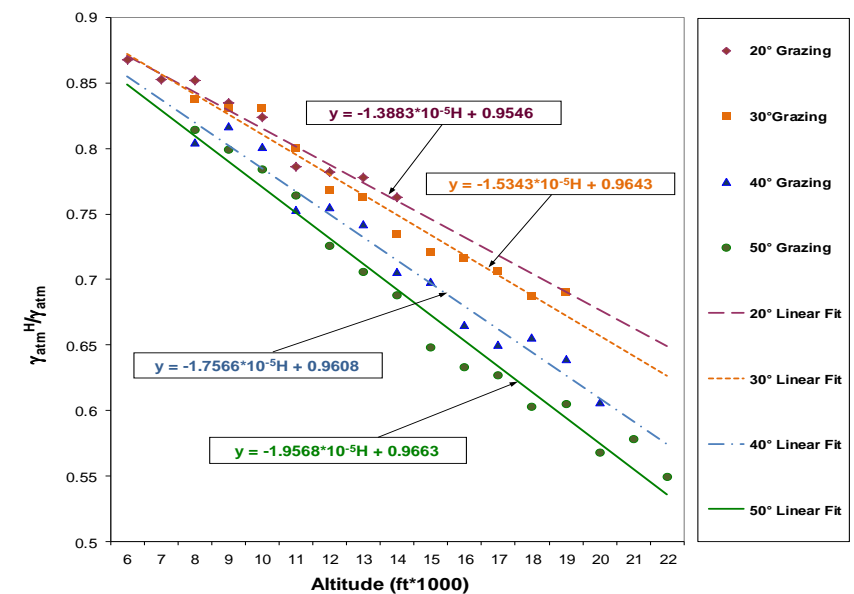

Fig. 33. $\gamma_{\mathrm{atmH}} / \gamma_{\mathrm{atm}}$ relationship as a function of altitude and grazing angle. 


\section{CONCLUSIONS AND FUTURE WORK}

The PILASTER Design, Development, Test and Evaluation (DDT\&E) activities were highly instrumental for a number of concomitant and subsequent research and development projects. In particular, these DDT\&E activities established solid foundations for research on laser target designators and Light Detection and Ranging (LIDAR) systems for different applications. The methods and algorithms developed for the calculation of eye-safe operational profiles were further developed in the NATO research and development groups and, after their publication [1, 11], they were adopted as reference material for international military and civil safety standards. The significant amount of data collected in the various test campaigns led to the development of a Laser Propagation Database (LPD), for a progressive refinement and validation of the PILASTER atmospheric propagation models in all representative weather conditions and operational scenarios. This database and the associated models led to the development of new remote sensing systems employing both monostatic and bistatic LIDAR techniques and proposed for a variety of applications including gaseous/aerosol pollutant concentration measurements and extra-terrestrial atmospheric sounding [1, 12, 24-26]. The development, test and validation of a new Laser Obstacle Avoidance and Monitoring (LOAM) system for helicopter low-level flight was also performed [1, 27-29] and further developments are currently ongoing to address the LOAM Human Machine Interface and Interaction $\left(\mathrm{HMI}^{2}\right)$ design, including the correct integration with forward looking IR/radar sensors and Night Vision Imaging Systems (NVIS) [30-35]. Additionally, a scalability and tailoring study is currently ongoing to investigate the potential of LOAM technology on small-to-medium size Unmanned Aircraft (UA) platforms. This study is also addressing the potential contributions of LIDAR sensors to the development of integrated avionics architectures for non-cooperative UA Sense-and-Avoid [36, 37]. To provide the high level of integrity required in laser flight test and training missions, the potential of a novel Avionics Based Integrity Augmentation System (ABIA) is being investigated for both manned and unmanned aircraft range operations [38-40]. Finally, research efforts are being devoted to the implementation of multiobjective trajectory optimisation techniques for tactical mission-planning and real-time aircraft flight management, fulfilling the requirements of current and likely future manned and unmanned aircraft operational scenarios [41-44].

\section{ACKNOWLEDGMENT}

The original research, development, test and evaluation activities described in this paper were funded by the Italian Ministry of Defence (MoD). The authors wish to thank the personnel of SELEX-ES, LOT-ORIEL, the Italian Air Force Flight Test Centre, and the PISQ Experimental and Training Range for helping in the preparation and execution of the ground and flight test activities.

\section{REFERENCES}

[1] R. Sabatini and M. A. Richardson, RTO AGARDograph AG-300 Vol. 26: Airborne Laser Systems Testing and Analysis: NATO Science and Technology Organization, 2010.
[2] R. Sabatini, "Tactical Laser Systems Performance Analysis in Various Weather Conditions", presented at the E-O Propagation, Signature and System Performance under Adverse Meteorological Conditions Considering Out of Area Operations, Sensors and Electronics Technology (SET) panel, NATO Research and Technology Organization (RTO), Naples, Italy, 1998.

[3] R. Sabatini, "High Precision DGPS and DGPS/INS Positioning for Flight Testing", in RTO-MP-43 - 6th Saint Petersburg International Conference on Integrated Navigation Systems, pp. 18-1 to 18-17, CSRI "Elektropribor" / AIAA / Systems Concepts and Integration (SCI) panel, NATO Research and Technology Organization (RTO), Saint Petersburg, Russia, 1999.

[4] R. Sabatini, F. Guercio, and S. Vignola, "Airborne Laser Systems Performance Analysis and Mission Planning", in RTO-MP-46 Advanced Mission Management and Systems Integration Technologies for Improved Tactical Operations, Systems Concepts and Integration (SCI) panel, NATO Research and Technology Organization (RTO), Florence, Italy, 1999.

[5] R. Sabatini, F. Guercio, G. Campo, and A. Marciante, "Laser Guided Bombs and Convertible Designation Pod Integration on Italian TORNADO-IDS", presented at the 31st Annual Symposium of the Society of Flight Test Engineers, Turin, Italy, 2000.

[6] R. Sabatini, F. Guercio, G. Campo, and A. Marciante, "Simulation and Flight Testing for Integration of a Laser Designation Pod and Laser Guided Bombs on Italian TORNADO-IDS", in RTO-MP-083 Integration of Simulation with System Testing, Systems Concepts and Integration (SCI) panel, NATO Research and Technology Organization (RTO), Toulouse, France, 2001.

[7] R. Sabatini and G. B. Palmerini, RTO AGARDograph AG-160 Vol. 21: Differential Global Positioning System (DGPS) for Flight Testing: NATO Science and Technology Organization, 2008.

[8] R. Sabatini, L. Rodriguez Salazar, A. Kaharkar, C. Bartel, and T. Shaid, "Carrier-phase GNSS Attitude Determination and Control System for Unmanned Aerial Vehicle Applications", ARPN Journal of Systems and Software, vol. 2, pp. 297-322, 2012

[9] R. Sabatini, L. Rodriguez Salazar, A. Kaharkar, C. Bartel, T. Shaid, and D. Zammit-Mangion, "Low-cost navigation and guidance systems for unmanned aerial vehicles - part 2: attitude determination and control", Annual of Navigation, vol. 20, pp. 97-126, 2013. DOI: 10.2478/aon2013-0008

[10] R. Sabatini, L. Aulanier, H. Rutz, M. Martinez, L. Foreman, B. Pour, et al., "Multifunctional information distribution system (MIDS) integration programs and future developments", in proceedings of IEEE Military Communications Conference 2009 (MILCOM2009), Boston, MA, 2009. DOI: 10.1109/MILCOM.2009.5379806

[11] R. Sabatini and M. A. Richardson, "A new approach to eye-safety analysis for airborne laser systems flight test and training operations", Optics and Laser Technology, vol. 35, pp. 191-198, 2003. DOI: 10.1016/S0030-3992(02)00171-8

[12] R. Sabatini and M. A. Richardson, "Novel atmospheric extinction measurement techniques for aerospace laser system applications", Infrared Physics and Technology, vol. 56, pp. 30-50, 2013. DOI: 10.1016/j.infrared.2012.10.002

[13] T. Elder and J. Strong, "The infrared transmission of atmospheric windows", Journal of the Franklin Institute, vol. 255, pp. 189-208, 1953

[14] R. M. Langer, "Report on Signal Corps Contract No. DA-36-039-SC$72351 ", 1957$.

[15] W. E. K. Middleton, "Vision through the Atmosphere", University of Toronto Press 1952.

[16] American National Standard Institute ANSI Z136.1, "Safe Use of Laser", 1976.

[17] American National Standard Institute ANSI Z136.4, "Laser Safety Measurements and Instrumentation”, 1990.

[18] STANAG 3606 - 5th ed., "Evaluation and Control of Laser Hazards", 1991.

[19] International Electrotechnical Commission IEC 825 - (Amendment 2), "Radiation Safety of Laser Products, Equipment Classification, Requirements and User's guide”, 1993.

[20] Italian Regulation DL 04.12.1992 - n. 475, “Attuazione della direttiva 89/686/CEE relativa ai dispositivi di protezione individuale”, 1992. 
[21] Italian Standard CEI - 76/2 - 2nd ed., "Apparecchi Laser - Sicurezza delle Radiazioni, Classificazione dei Materiali, prescrizioni e Guida per l'Utilizzatore", 76/2 - ed. II, 1993.

[22] Italian Military Safety Standard SMD-W-001 - 2nd ed., "Regolamento Interforze di Sicurezza per l'Impiego degli Apparti Laser”, 1995.

[23] UK Ministry of Defence - Ordnance Board D/OB/2407/2, JSP390 Military Laser Safety, 1998.

[24] R. Sabatini and M. A. Richardson, "Innovative methods for planetary atmospheric sounding by lasers", in proceedings of AIAA Space 2008 Conference, San Diego, CA, USA, 2008. DOI: 10.2514/6.2008-7670

[25] R. Sabatini, M. A. Richardson, H. Jia, and D. Zammit-Mangion, "Airborne laser systems for atmospheric sounding in the near infrared", in proceedings of SPIE 8433, Laser Sources and Applications, Photonics Europe 2012, Brussels, Belgium, 2012. DOI: 10.1117/12.915718

[26] A. Gardi and R. Sabatini, "Unmanned aircraft bistatic lidar for CO2 colum density determination", in proceedings of IEEE Metrology for Aerospace Conference 2014, Benevento, Italy, 2014

[27] R. Sabatini, E. Roviaro, and M. Cottalasso, "Development of a Laser Collision Avoidance System for Helicopters: Obstacle Detection/Classification and Calculation of Alternative Flight Paths", in RTO-MP-092 - Complementarity of Ladar and Radar, Sensors \& Electronics Technology (SET) panel, NATO Research and Technology Organization (RTO), 2002.

[28] R. Sabatini, A. Gardi, and M. A. Richardson, "LIDAR Obstacle Warning and Avoidance System for Unmanned Aircraft", International Journal of Mechanical, Industrial Science and Engineering, vol. 8, pp. 62-73, 2014

[29] R. Sabatini, A. Gardi, S. Ramasamy, and M. A. Richardson, "A laser obstacle warning and avoidance system for manned and unmanned aircraft", in proceedings of IEEE Metrology for Aerospace Conference 2014, Benevento, Italy, 2014

[30] R. Sabatini, C. Bartel, A. Kaharkar, and T. Shaid, "Design and integration of vision based sensors for unmanned aerial vehicles navigation and guidance", in proceedings of SPIE 8439, Optical Sensing and Detection II, Photonics Europe 2012, Brussels, Belgium, 2012. DOI: $10.1117 / 12.922776$

[31] R. Sabatini, M. A. Richardson, M. Cantiello, M. Toscano, P. Fiorini, H. Jia, et al., "Night Vision Imaging Systems design, integration and verification in military fighter aircraft", in proceedings of SPIE 8439, Optical Sensing and Detection II, Photonics Europe 2012, Brussels, Belgium, 2012. DOI: 10.1117/12.915720

[32] R. Sabatini, C. Bartel, A. Kaharkar, T. Shaid, L. Rodriguez Salazar, D. Zammit-Mangion, et al., "Low-cost navigation and guidance systems for unmanned aerial vehicles - part 1: vision-based and integrated sensors", Annual of Navigation, vol. 19, pp. 71-98, 2012. DOI: 10.2478/v10367012-0019-3

[33] R. Sabatini, S. Ramasamy, A. Gardi, and L. Rodriguez Salazar, "Lowcost sensors data fusion for small size unmanned aerial vehicles navigation and guidance", International Journal of Unmanned Systems Engineering, vol. 1, pp. 16-47, 2013. DOI: 10.14323/ijuseng.2013.11
[34] R. Sabatini, M. A. Richardson, M. Cantiello, M. Toscano, and P. Fiorini, "A novel approach to night vision imaging systems development, integration and verification in military aircraft", Aerospace Science and Technology, 2014. DOI: 10.1016/j.ast.2013.08.021

[35] R. Sabatini, C. Bartel, A. Kaharkar, T. Shaid, and S. Ramasamy, "Navigation and Guidance System Architectures for Small Unmanned Aircraft Applications", International Journal of Mechanical, Industrial Science and Engineering, vol. 8, pp. 733-752, 2014

[36] L. Rodriguez Salazar, R. Sabatini, A. Gardi, and S. Ramasamy, "A Novel System for Non-Cooperative UAV Sense-and-Avoid", in proceedings of European Navigation Conference 2013 (ENC2013), Vienna, Austria, 2013

[37] S. Ramasamy, R. Sabatini, and A. Gardi, "Avionics Sensor Fusion for Small Size Unmanned Aircraft Sense-and-Avoid", in proceedings of IEEE Metrology for Aerospace Conference 2014, Benevento, Italy, 2014

[38] R. Sabatini, T. Moore, and C. Hill, "A new avionics-based GNSS integrity augmentation system: Part 1 - Fundamentals", Journal of Navigation, vol. 66, pp. 363-384, 2013. DOI: 10.1017/S0373463313000027

[39] R. Sabatini, T. Moore, and C. Hill, "A new avionics-based GNSS integrity augmentation system: Part 2 - Integrity flags", Journal of Navigation, vol. 66, pp. 501-522, 2013. DOI: 10.1017/S0373463313000143

[40] R. Sabatini, T. Moore, and C. Hill, "Avionics-based integrity augmentation system for mission- and safety-critical GNSS applications", in proceedings of 25th International Technical Meeting of the Satellite Division of the Institute of Navigation 2012, (ION GNSS 2012), Nashville, TN, 2012, pp. 743-763

[41] K. Chircop, D. Zammit-Mangion, and R. Sabatini, "Bi-objective pseudospectral optimal control techniques for aircraft trajectory optimisation", in proceedings of 28th Congress of the International Council of the Aeronautical Sciences 2012 (ICAS2012), Brisbane, Australia, 2012, pp. 3546-3555

[42] W. Camilleri, K. Chircop, D. Zammit-Mangion, R. Sabatini, and V. Sethi, "Design and validation of a detailed aircraft performance model for trajectory optimization", in proceedings of AIAA Modeling and Simulation Technologies Conference 2012 (MST2012), Minneapolis, MN, USA, 2012. DOI: 10.2514/6.2012-4566

[43] S. Ramasamy, R. Sabatini, A. Gardi, and Y. Liu, "Novel flight management system for real-time 4-dimensional trajectory based operations", in proceedings of AIAA Guidance, Navigation, and Control Conference 2013 (GNC2013), Boston, MA, USA, 2013. DOI: $10.2514 / 6.2013-4763$

[44] A. Gardi, R. Sabatini, S. Ramasamy, and K. de Ridder, "4-Dimensional Trajectory negotiation and validation system for the next generation air traffic management", in proceedings of AIAA Guidance, Navigation, and Control Conference 2013 (GNC2013), Boston, MA, USA, 2013. DOI: $10.2514 / 6.2013-4893$ 